
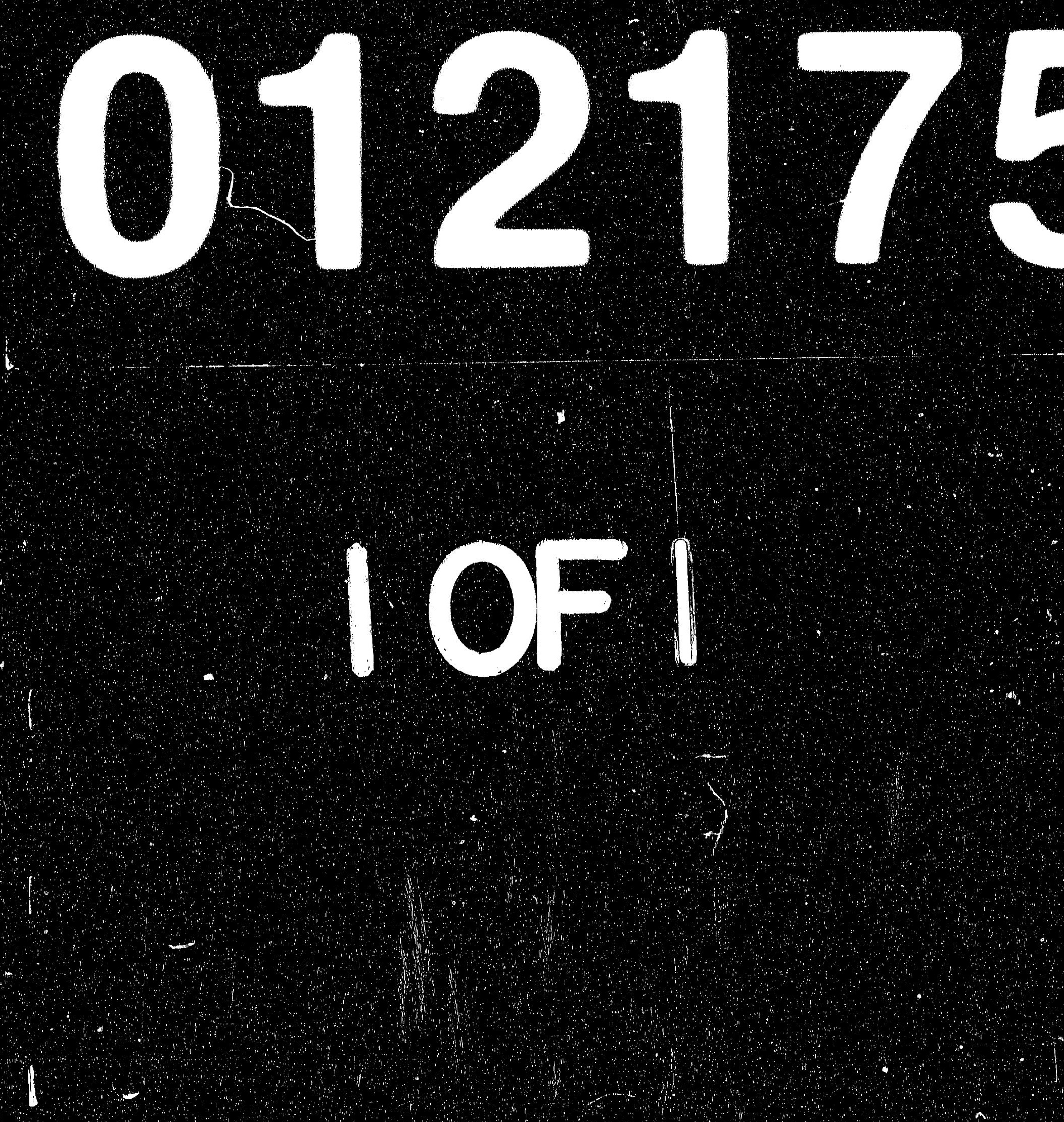

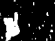

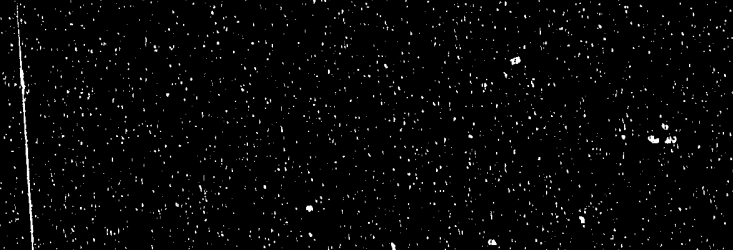

- lor
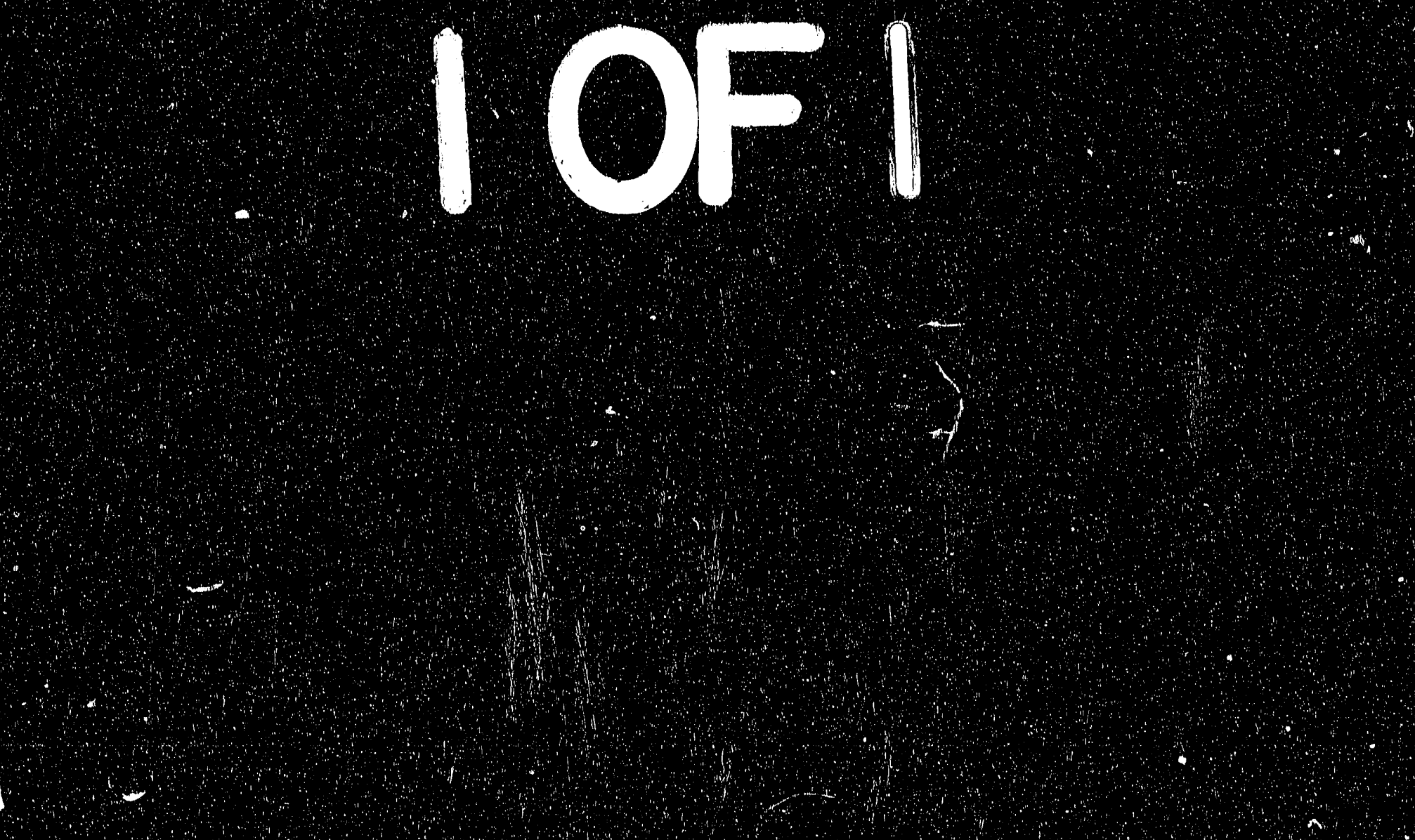

$\checkmark$

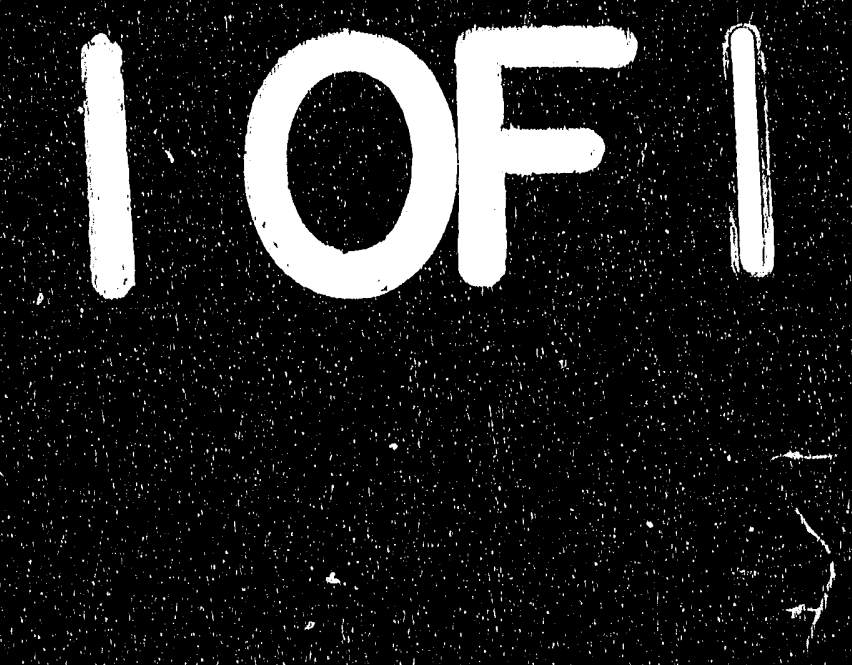

-
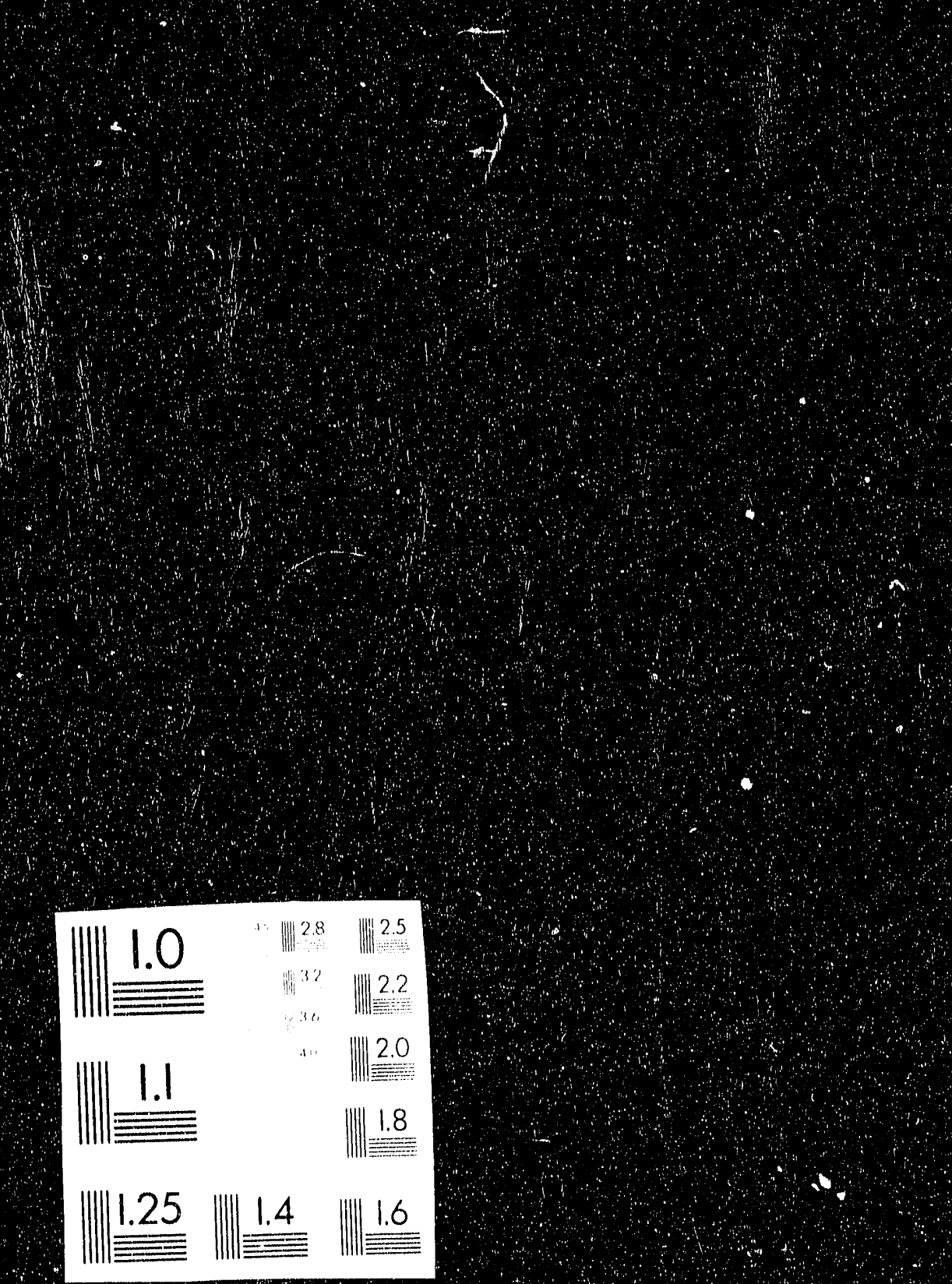


\title{
Dynamic Analysis of the 7-GeV APS Experiment Hall \\ Foundation based on \\ Equivalent Lumped Parameter Modeling
}

\author{
by \\ M. W. Wambsganss \\ N:aterials and Components Technology Division \\ Argonne National Laboratory
}

ANL./APS/IN/VIB--89/1

DE92 012175

\subsection{Introduction}

Soil-structure interaction characteristics (natural frequencies, vibration mode, and damping) determine the dynamic response of the 7-GeV APS experiment hall foundation and magnet/support structure to both external (ground motion) and internal (machinery and equipment located within the experimeni hall) excitation sources. Dynamic analysis procedures include those based on elastic half-space theory, impedance functions, and finite element methods.

Relatively simple expressions for foundation response have been developed by interpreting elastic half-space solutions in terms of the well-known mass-spring-dashpot vibration theory (Richart, Hall, and Woods, 1970). For the most part, these expressions have been developed and evaluated for rigid, circular machine foundations of modest size; for example, up to $\sim 16-\mathrm{ft}$ diameter. Spring and damping coefficients for a rigid, circular foundation resting on an elastic half-space are summarized in Table 1 (Richart, 1989).

In this technical note, mass-spring-dashpot, also referred to as equivalent lumped parameter, models are employed to model the soilfoundation interaction of two typical floor segments from the 7-GeV APS experiment hall. Equivalent lumped parameter models have the advantage of being easy to apply and of readily allowing for parameter studies.

Analysis requires knowledge of certain properties of the soil including density, shear wave velocity, and Poisson's ratio, as well as knowledge of the degree of homogeneity of the underlying soil stratum. These data for the APS site were determined by a geotechnical investigation (STS Consultants, 1988). A soil profile and pertinent data, obtained from crosshole seismic testing, are given in Appendix 1.

Natural frequencies and damping are calculated for the vertical, sliding, rocking, and coupled rocking/sliding modes of vibration. 
Subsequently, various corrections to account for modeling "dsficiencies" are considered and their influences evaluated.

The equivalent lumped parameter models were developed for machine foundations which, compared with the APS foundation, are smaller in plan dimensions and larger in ratio of height to characteristic plan dimension. Therefore, the applicability of these models in the analysis of the dynamic characteristics of the AP:s foundation must be established. The modeling is evaluated by applying the equivalent lumped parameter models in the analysis of large foundations (on the order of the APS foundation segments) for which test data exists. A comparison of theoretical and test results establishes the basis for an assessment of the applicability and accuracy of the modeling.

\subsection{7-GeV APS Experiment Hall}

The APS experiment hall is a large ring-shaped structure. For analysis purposes, the experiment hall basemat can be considered to be made up of individual segments defined by expansion joints between poured concrete floor segments. As illustrated in Figs. 1a and 1b, the current design is such that the ring-shaped experiment hall foundation is divided into 40 cells (9-deg sectors) separated by radial expansion joints. An individual 9-deg sector is further divided by a "circumferential" expansion joint between the 2 -ft thick basemat supporting the shielding and magnet/supports and the $1-\mathrm{ft}$ thick basemat comprising the remainder of the experiment hall floor as shown in Figs. $1 b$ and $1 c$; a cross-section through the experiment hall is given in Fig. 2. Consequently, in analysis it is only necessary to consider two foundation structures, and these can be considered individually, as uncoupled structures.

As shown in Fig. 1c, the two separate foundation structures are designated APS-1, for the $1-\mathrm{ft}$ thick segment, and APS-2, for the 2 - $\mathrm{ft}$ thick segment supporting the shielding and magnets. The basemats of each are approximated as rectangles of dimensions given in Table 2. Equivalent circular radii for the translational (vertical or sliding) and rocking modes are computed from the formulae of Table 1 and are listed in Table 2. The mass and mass moment of inertia about an axis parallel to the long dimension of the rectangle, positioned at the midpoint of the width, are also given in Table 2.

Soil profiles were developed from borings as part of the geotechnical investigation. As given in the STS Consultants report (1988) 
and summarized in Appendix 1-A, the major geologic units encountered below the surficial topsoil are as follows: fill materials (in various locations), weathered till, unweathered till, outwash deposits (encountered sporadically across the site), Lemont drift, and bedrock. The bedrock surface ranges in elevation from 613 to 646 feet. With the surface elevation of the APS foundation at 740 feet, the average depth to bedrock is 110 feet $(33.5 \mathrm{~m})$.

Results from the crosshole seismic tests are tabulated in Appendix 1-B. Shear wave velocity, the most important of the soil dynamic properties, is plotted in Figs. A.1 - A.4 as a function of depth for each of the four bore hole locations. For analysis purposes, the soil stratum above bedrock will be assumed to be homogeneous with properties determined as the average of twelve measurements of soil density $p$ and shear wave velocity $V_{S}$ taken at depths of 10,15, and 20 feet for each of the four crosshole seisinic test locations; these averaged values are given in Table 2.

Assuming that the foundation is rigid and that the soil is representative $\mathrm{Jf}$ an elastic half-space, the relationships given in Table 1 apply. Using these relationships, together with the data of Table 2, values of spring constants $k$, mass ratios $B$, and damping ratios $D$, are calculated for the vertical, sliding, and rocking modes of vibration; it should be noted that a Poisson's ratio of 0.4 is assumed rather than using values computed from measurements of compression and shear wave velocities as such calculations involve the differencing of two large numbers and inaccuracies are inherent (Richart, 1987). These coefficients are given in Table 3. With this information, the undamped natural frequencies for the various modes can be readily calculated as follow:

$$
\begin{array}{ll}
\text { Vertical mode: } & f_{z}=1 / 2 \pi\left[k_{z} / m\right]^{1 / 2} \\
\text { Sliding mode: } & f_{x}=1 / 2 \pi\left[k_{x} / m\right]^{1 / 2} \\
\text { Rocking mode: } & f_{\psi}=1 / 2 \pi\left[k_{z} / /_{\psi}\right]^{1 / 2}
\end{array}
$$

The calculated values for undamped natural frequencies and damping ratios are also given in Table 3.

It should be realized, as pointed out by Richart et al (1970), that a pure sliding mode can not exist in practice because it requires that the center of gravity of the foundation be on the line of the horizontal restraining force. Theorotically, this requires that the foundation must be 
infinitely thin since the restraining force is developed at the interface between the foundation and the ground.

Practically, for cases involving relatively thin foundations, the sliding and rocking mode frequencies are sufficiently separated that the modes can be assumed to be uncoupled. However, in many cases it will be necessary to consider the coupled modes. With mode coupling, the coupled frequencies always lie outside the uncoupled frequencies, viz., above the higher uncoupled frequency and below the lower uncoupled frequency.

Following the development of Richart et al (1970) (see Appendix 3), the undamped coupled rocking/sliding mode natural frequencies can be expressed in terms of the sliding mode frequency $f_{x}$ as

$$
f_{\psi x}=\beta_{n} f_{x}
$$

where,

$$
\begin{gathered}
\beta_{1}=\left\{1-1 /\left[1-\left(r / h_{0}\right)^{2}+\left(1 / h_{0}\right)^{2}\left(k_{\psi} / k_{x}\right)\right]\right\}^{1 / 2} \\
\beta_{2}=\left\{\left[\left(1 / r^{2}\right)\left(k_{\psi} / k_{x}\right)+\left(h_{0} / r\right)^{2}\right]-1 /\left[1-\left(r / h_{0}\right)^{2}+\left(1 / h_{0}\right)^{2}\left(k_{\psi} / k_{x}\right)\right]\right\}^{1 / 2}
\end{gathered}
$$

Coupled rocking/sliding mode natural frequencies for the APS foundations as computed from Eq. (4), are also given in Table 3.

The above referenced calculations, using the relationships given in Table 1, and summarized in Table 3, are based on the assumptions that (a) the spring and damping coefficients are constant and independent of frequency, (b) the soil is representative of an elastic half-space, i.e., there is no "layering", and (c) the foundation, or basemat, is rigid. In reality, none of these assumptions is strictly valid. Therefore, in the following, first approximations to account for the lack of applicability of these assumptions are considered.

2.1 Frequericy dependence of coefficients. In general, the spring and damping coefficients are not constant but are a function of frequency, which can be represented in non-dimensional form as

$$
a_{0}=\omega b / V_{s}
$$

where $\omega(=2 \pi f)$ is frequency and $b$ is a characteristic dimension such as radius of a circular foundation or half-width of a rectangular foundation dimension. 
To account for the reality that stiffnesses decrease with frequency, Zazetas (1983) notes that Whitman and Richart (1967) recommend that a fictitious mass (mass moment of inertia) be added to the actual foundation mass (mass moment of inertia) such that Eqs. (1) - (3) become

$$
\begin{array}{ll}
\text { Vertical Mode: } & \left(f_{z}\right) F=1 / 2 \pi\left[k_{z} / m\left(1+0.27 / B_{z}\right)\right]^{1 / 2} \\
\text { Sliding Mode: } & \left(f_{x}\right) F=1 / 2 \pi\left[k_{x} / m\left(1+0.095 / B_{x}\right)\right]^{1 / 2} \\
\text { Rocking Mode: } & \left(f_{\psi}\right)_{F}=1 / 2 \pi\left[k_{\psi} / I_{\psi}\left(1+0.24 / B_{\psi}\right)\right]^{1 / 2}
\end{array}
$$

where subscript $F$ denotes correction for frequency-dependent effects. CF as

Equations (6) - (8) can be expressed in terms of a "correction factor"

$$
\begin{array}{ll}
\left(f_{Z}\right) F=f_{Z}(C F) ; & (C F)_{Z}=\left(1+0.27 / B_{Z}\right)^{-1 / 2} \\
\left(f_{X}\right)_{F}=f_{X}(C F) ; & (C F)_{X}=\left(1+0.095 / B_{X}\right)^{-1 / 2} \\
\left(f_{\psi}\right)_{F}=f_{\psi}(C F) ; & (C F)_{\psi}=\left(1+0.24 / B_{\psi}\right)^{-1 / 2}
\end{array}
$$

The correction factor $\mathrm{CF}$ is given in Table 4 for the various vibration modes. Because of the relatively small values of mass ratio $B$, the correction can be significant. This brings into question the applicability of the correction for small values of mass ratio.

2.2 Layering. Richart (1988a) notes that "The first improvement on the elastic half-space theory is to consider a foundation supported by an elastic, homogeneous, isotropic layer which rests on a rigid base". The presence of the rigid base has the effect of increasing the stiffness (natural frequencies) of the soil-foundation system and decreasing the damping. In the analysis of the APS experiment hall foundation, the rigid base is represented by bedrock. The relationships for increased stiffness as a function of the ratio of the thickness of the elastic layer $\mathrm{H}$ to the radius of the basemat $r_{0}$ are as follow (Richart, 1989)

$$
\begin{array}{ll}
\text { Vertical mode: } & k_{z L}=k_{z}\left(1+1.3 \mathrm{roz}_{\mathrm{O}} / \mathrm{H}\right) \\
\text { Sliding Mode: } & k_{x L}=k_{x}\left(1+r_{0 x} / 2 \mathrm{H}\right) \\
\text { Rocking mode: } & k_{\psi L}=k_{\psi}\left(1+r_{0} / 6 \mathrm{H}\right)
\end{array}
$$


The increase in frequency is proportional to the square root of the term in parenthesis and a correction factor $\mathrm{CL}$ can be defined accordingly as

$$
C L=(K L / K)^{1 / 2}
$$

Correction factors for layering are summarized in Table 4 for the various modes associated with the two APS foundation segments; in performing the calculations it is assumed that $H=33.5 \mathrm{~m}$.

In a layered system, geometric damping is significantly reduced as the wave energy reflects back and forth between the bottom of the foundation and the bedrock surface, rather than being radiated away. The depth of soil defining the limits for neglect of layering effecis on damping depends on the particular vibration mode; for vertical vibration the critical soil depth is $6 r_{0}$, while for rocking mode vibration it is $(2-2.5) r_{0}$. As an example, for vertical motion of a foundation the decrease in damping factor which can be expected is given in Table 5 and plotted in Fig 3 (Richart 1989).

2.3 Foundation flexibility. The equivalent lumped parameter model was developed based on the assumption of a rigid foundation. For the sliding and torsional vibration modes this assumption is valid as the in-plane rigidity of a mat foundation will be large compared to the deformability of the soil. However, as Gazetas (1983) notes ".....in many practical situations, the foundation response to vertical and rocking loading cannot be properly predicted without accounting for the finite out-of-plane (flexural) rigidity of the mat."

The dimensionless parameter controlling the response of flexible foundations is the relative rigidity factor RF (Gazetas, 1983),

$$
R F=\left(E_{f} / E_{S}\right)\left(1-v_{f^{2}}\right)(t / b)^{3}
$$

where, $E_{f}$, uf, $t$, and $b$ are, respectively, the Young's modulus, Poisson's ratio, thickness, and characteristic dimension (radius or half-width) of the mat foundation. The distribution of the loading will also appreciably affect the dynamic characteristics and response of flexible foundations. Calculated values of RF for the two APS foundations are given in Table 2.

The rigidity factors given in Table 2 for the APS-2 basemat neglect the contribution of the shielcing to the rigidity of the basemat. In actuality, it may be reasonable to consider the shielding and basemat as 
an integral structure, as illustrated in Fig. 2. In that case, the assumption of a rigid structure may be valid.

Gazetas (1983) suggests that the main influence of a decreasing RF (increasingly flexible foundation) on the response of a mat foundation is materialized through the corresponding decrease of the static stiffnesses. For verical vibrations, and two different assumed load distributions, results developed by Gazetas (1983) lead to the frequency correction factors for rigidity $(C R)_{z}$ given in Table 4 , defined as

$$
\left(f_{z}\right) R=f_{z}(C R)_{z}
$$

2.4 Discussion of results. Natural frequencies and damping for the two APS foundations are given in Table 3, as calculated from Eqs. (1) (3) Using the the relationships given in Table 1. One observes that the natural frequencies associated with the APS-1 foundation are approximately 2 times greater than those of the APS-2 foundation. This is the result of the APS-1 foundation having a lower mass value and a higher spring constant (due to a larger equivalent radius).

Since the APS-1 foundation is a relatively thin foundation, the sliding and rocking modes can be considered uncoupled. This is confirmed by the fact that the two computed coupled rocking/sliding mode frequericies are essentially equal to the uncoupled sliding and rocking mode frequencies as shown in Table 3.

However, for the APS-2 foundation with the shielding and basemat considered to be integral, the height-to-base ratio is approximately 0.5 , and coupling of the rocking and sliding modes is possible as discussed above. Accounting for the potential for coupling, the sliding mode frequency can be considered to be reduced flom 17.3 to $15.9 \mathrm{~Hz}$ and the rocking mode increased from 27.6 to $33.4 \mathrm{~Hz}$.

Calculated damping values are very high - one might conclude unrealistically high for APS-1 foundation. The large damping values can readily be traced to the dependence of damping ratio $D$ on mass ratio $B$ and the fact that the mass ratio is inversely proportional to the equivalent radius to the 3 rd and 5 th powers, respectively, for translational and rocking modes; see Table 1 . The validity of the damping ratio calculation is subject to question as Richart et al (1970) note "....these approximations (equivalent lumped parameter models) give good answers only for $B \geq 1$." Nevertheless, it should be noted that more recently 
Richart (1988b) expressed the opinion that the modeling should be valid for $B<1$ as well.

As illustrated in Fig. 4, damping determines the magnification factor $Q$ and the resonant frequency $f_{r}$. For ground motion excitation, assuming a constant excitation force, the magnification factor is given by

$$
Q=1 /\left[2 D\left(1-D^{2}\right)^{1 / 2}\right], \quad D<0.707
$$

note that for $D>0.707$ there is no amplification. In terms of damping factor the resonant frequency is given by

$$
f_{r}=\left[\left(1-2 D^{2}\right)^{1 / 2}\right] f_{n}
$$

In Table 3, amplification factors and resonant frequencies, determined from the calculated damping factors, are given for the two cases in which the damping factor is less than 0.707 . While the amplification is modest $(1.06$ and 1.10$)$, the reduction in frequency at which the peak amplitude occurs is substantial (17.3 to $11.2 \mathrm{~Hz}$ for APS-2 sliding mode and 27.6 to $15.8 \mathrm{hz}$ for APS-2 rocking mode). Again, these damping values and the results derived from their use should be used with caution.

Recommended correction factors for frequency-dependence, layering, and flexural rigidity aro given in Table 4. Their effect on soilfoundation natural frequencies can be readily assessed from the results in Table 4.

The correction for frequency dependence of the stiffness, using a fictitious mass, represents a substantial correction - as large as a factor of 0.2 reduction in natural frequency. The magnitude of the correction can be traced to the dependence of the correction factor on mass ratio and, as discussed above, the fact that it varies inversely with equivalent radius to the 3rd or 5th power. As with the damping calculation, the question of whether or not the recommiended corrections are valid for small mass ratios arises.

The corrections for layering (an elastic soil over a rigid base), on the other hand, seem "reasonable". The increase in soil-foundation frequency ranges from 2 to 21 per cent. 
The rigidity factors (RF) for the APS foundations are tabulated in Table 2. It is observed that they are quite low indicating that the foundation should be treated as a flexible foundation or, as a minimum, that the flexibility of the foundation should be accounted for with some type of validated correction. This implies implicitly that the distribution of the loading will also be important. Based on the results of Gazetas (1983), the correction factor for the vertical vibration mode ranges from 0.66 to 0.85 dependent on the particular APS foundation and the assumed load distribution (uniform and parabolic are considered by Gazetas). However, as noted above, if the APS-2 basemat and shielding are considered integral, it may be reasonable to consider the APS-2 foundation rigid.

\subsection{Modeling Evaluation - Large Foundations}

Equivalent lumped parameter models are simple models that are being used to analyze verv complex soil-structure interaction systems. The models have been shown to give good results for problems in which the parameters are in the range for which the models and associated "corrections" were developed. However, as apparent from the above discussion, it remains to verify the applicability of such models to basemat structures of the size of the APS foundation segments. Therefore, before interpreting and applying the results of the analyses of the APS experiment hall foundations, an attempt will be made to evaluate the modeling based on test data from comparable large foundations.

There is only limited test data available in the literature on the dynamic characteristics of large foundations (lguchi et al, 1988; Ishida, 1985; and Srinivasan et al, 1989). The dimensions of these foundations including their mass, mass moment of inertia, pertinent soil properties, and flexural rigidity factors are given in Table 2, where these parameters can be compared with those of the APS foundations.

The soil profile for Iguchi's models (Iguchi et al, 1988) is sandy gravel (3-5 m), fine sand with gravel (5-14 $\mathrm{m})$, and mudstone with sandstone $(14-100 \mathrm{~m})$. It should be noted inat the Iguchi model with basemat size of $16 \mathrm{~m} \times 16 \mathrm{~m} \times 3 \mathrm{~m}$ is very close to the APS-2 foundation when one considers the equivalent radius $(9.03 \mathrm{~m}$ vs. $8.63 \mathrm{~m}$, for translational modes) and the foundation mass $\left(1.85 \times 10^{6} \mathrm{~kg}\right.$ vs. $\left.9.72 \times 10^{5} \mathrm{~kg}\right)$. Also, the soil density $\left(1.9 \times 10^{3} \mathrm{~kg} / \mathrm{m}\right)$ and shear modulus $(=300 \mathrm{~m} / \mathrm{s})$ are comparable. 
With regard to Ishida's tests (Ishida 1985), it should be noted that the models are located on base rock with very high shear wave velocities $(1,000$ to $1,600 \mathrm{~m} / \mathrm{s})$. Also, two of the sites are "layered" while the other two sites Ishida notes, "seem to be half-space media". Based on the phasing of the accelerometer measurements, and as the geometry of the foundations tested would indicate, Ishida is exciting a coupled rocking/ sliding mode in his tests.

The site for Srinivasan's model (Srinivasan et al, 1989) is characterized by soil layers. These layers consist of silty sands, sandy silts, clayey silts, and silty clays. The soil layer underlying the basemat had a depth ranging from 4 to $10 \mathrm{~m}$ and consisted of silty fine sands and sandy silts.

All foundations are analyzed the same way. Regardless of layering, that is known to be present in some of the soil systems, an elastic halfspace is assumed. With the exception of the foundation tested by Srinivasan et al (1989), the flexural rigidity factors of the foundations are significantly greater than one. For this analysis it will be assumed that all the foundations are rigid. Further, stiffness and spring coefficients will initially be assumed constant (independent of frequency), therefore, the relationships given in Table 1 are taken to apply with no correction. Computed values of natural frequencies, mass ratios, and damping values are given in Table 6 . Resonant frequencies and damping ratios determined from tests are also listed in Table 6 to allow for comparison with theoretical predictions.

A comparison of the results given in Table 6 reveals that the computed natural frequencies are in reasonable agreement with test results considering the complexity of the physical situation and the relative simplicity of the modeling. In all cases but one (Ishida $5 \times 5 \times 7 \mathrm{~m}$ basemat) the calculated results are greater than the test results. For Iguchi's and Ishida's models, the factor ranges from 1.09 to 1.54 ; for Srinivasan's model the factor ranges from 2.13 to 2.89 .

The predicted damping values are generally greater than measured values by a factor of up to approximately 3 in several cases. Here, again, it should be noted that the mass ratios $B$ are small as a result of the large values for equivalent radii. However, with regard to damping, it should also be recognized that damping is inherently a difficult parameter to measure - unlike frequencies which can be determined with reasonable accuracy by measurement. 
As discussed in Section 2.0, there are frequency, layering, and rigidity effects that will influence the computed natural frequencies. These have not been included in the lumped parameter modeling of the large foundations reported in Table 6 . Frequency and rigidity effects will tend to decrease the natural frequency while layering tends to increase the natural frequency; these effects can be observed from Table 4 for the APS foundations. In Table 7, correction factors for frequency CF are tabulated for the large foundations of Iguchi, Ishida, and Srinivasan et al, and the corrected frequencies $f_{F}$ are also given together with the measured frequencies. For the most part, this correction tends to improve argreement between theory and test. Again, neglecting one of Ishida's models (Ishida $5 \times 5 \times 7 \mathrm{~m}$ basemat), predicted values are within $\pm 15 \%$ of test results for Niwa's and Ishida's models; this can be considered excellent agreement. In comparison with Srinivasan's test results, the corrected frequencies are from 15 to $90 \%$ greater, again, a significant improvement.

It should be noted that the calculated frequencies are undamped natural frequencies, whereas the measured frequencies represent resonant frequencies. For a constant force excitation, the resonant frequency will be less than the undamped natural frequency, the amount less depending on the system damping; see Fig. 4 and Eq. (19). However, when the excitation force is an unbalanced rotating mass, as in the case of the three test studies considered herein, the excitation force is proportional to $\omega^{2}$, i.e.,

$$
F=m_{r} e \omega^{2}
$$

where $m$ is the unbalanced mass and $e$ is the eccentricity. In this case, the amplification curves are as shown in Fig. 5. The resonant frequency is greater than the undamped natural frequency and in terms of damping factor can be expressed as

$$
f_{r}=1 /\left[\left(1-2 D^{2}\right)^{1 / 2}\right]_{n}
$$

Rather than use the calculated damping values, which we are not confident of, to predict resonant frequencies, we can use the actual (measured) damping values to calculate what would be the undamped natural frequencies for the systems, corresponding to a given resonant frequency. Results of this exercise are given in Tables 6 and 7 . With three exceptions, the correction makes the agreement between theory and test slightly worse since the measured resonant frequencies were already less than the computed (theoretical) undamped natural frequencies. 
As discussed above, the effect of layering is to reduce damping. This may be a factor in some of the cases studied. However, no attempt was made to correct for such an effect, say, using the data of Table 5 or Fig. 3. It should be noted that the correction is of minor influence in rocking mode vibration.

In summary, the equivalent lumped parameter modeling, without correcting for frequency and layering effects, over-predicts the natural frequencies of 7 of the 8 large foundations studied. Nevertheless, for 6 of the models, considering the complexity of the physical situation, the predictions are reasonable, i. e., within 50 percent of the corresponding test results. If a correction, in the form of an added mass, for the frequency-dependency of the spring coefficient is included, the agreement between theory and test results is very good $( \pm 15 \%)$ for 6 of the models, and reasonable for the other two. With regard to the latter, the Ishida $5 \times 5 \times 7 \mathrm{~m}$ basemat is not typical of machine foundations as the height to base dimension is greater than 1. With regard to Srinivasan's model, it should be noted that the rigidity factor RF is less than 1; see Table 2 . In addition to the fact that we are "pushing the limits" for which the equivalent lumped parameter modeling was developed and validated, other poteritial sources of error are many including uncertainties in characterization of the soil properties.

\subsection{Discussion of Results}

Based on the generally good agreement between calculated and test results, it can be concluded that equivalent lumped parameter modeling, corrected to account for frequency dependence of the spring coefficients using Eqs. (9) - (11), is applicable for estimating the natural frequencies of large foundations, on the order of the APS foundations. However, for the APS-1 foundation, it remains to determine the applicability of the frequency correction for very small values of mass ratio $B$ as the correction is (unrealistically?) very large (0.2 and 0.15). Also, as can be noted from Table 1, the flexural rigidity factors for the APS foundations are much less than 1 implying that the flexibility of the foundation is important and should be included in the modeling. Here it should be noted that if the shielding and basemat are considered integral, it may be reasonable to assume APS-2 rigid.

The equivalent lumped parameter modeling provides useful insights to the dynamic behavior of the APS foundations, the identification of the parameters that are of importance in determining dynamic behavior, and the degree of dependence on these parameters. It also provides what can 
be considered a good estimate of expected natural frequencies for the various vibration modes of interest. The modeling then also provides a tool for designing (specifying the mass and dimensions of) the APS foundations to obtain desired dynamic characteristics, e.g., to avoid particular frequency ranges.

There is a degree of uncertainty in the measurement of shear wave velocity as can be observed from the data of Appendix 1. Additionally, it should be recognized that the crosshole seismic measurements provide shear wave velocities for the soil conditions existing at the time of the tests; these conditions will vary with the seasons of the year, the level of the water table, and the like. The shear modulus is calculated from the soil density $\rho$ and shear wave velocity $V_{S}$ according to the relationship

$$
G=\rho V_{S}^{2}
$$

The soil density used in this calculation is the soil density corresponding to the conditions under which the shear wave velocity was measured, viz., the "wet soil density". As these parameters are subject to variation with soil conditions, and relatively large variations are possible, it is instructive to determine how the natural frequency varies with a variation in these parameters: Since $f \propto(k)^{1 / 2}$, and $k \propto \rho V_{S}{ }^{2}$, it follows that $f \propto(\rho)^{1 / 2} V_{S}$. Consequently, if there is a $+1-10 \%$ variation in shear wave velocity, there would be $a+1-10 \%$ variation in frequency. Similarly, a $+1-10 \%$ variation in soil density will result in an approximate $+1-5 \%$ variation in frequency. However, it should be noted that these effects are of less importance in cohesive soils (Richart 1988), which is the case for the APS site.

Damping values are of importance as they dotermine the magnitude of the amplification. As illustrated in Fig. 4, low damping values can result in relatively large response amplitudes when the excitation frequency is in the vicinity of a soil-foundation interaction frequency. On the other hand, if the damping is sufficiently high, very little or no magnification will result and the importance of determining natural frequencies diminishes; for $D>0.707$, there are no amplitude peaks. As discussed above and as can be observed from Fig. 4, an increase in damping not only lowers the peak amplitude, it also causes it to occur at a lower frequency termed the resonant frequency $f_{r}$. Since damping factors can be relatively large, the effect of damping on resonant frequency can be important. The effects of damping on magnification factor $Q$ and resonant frequency $f_{r}$ as determined from Eqs. (18) and (19), respectively, are graphically presented in Fig. 6. 
From Table 3, one observes that the calculated damping ratios for the APS foundations are in general very high $(D>0.5$, This would imply, as can be determined from the curve of Fig. 6, that there is little if any potential for magnification of ground motion. However, as noted from Table 6, which compares calculated and test results, calculated damping values ior large foundations tend to be high relative to test data, and one has to make this statement with caution. In general, predictions based on calculated damping should be used as a guideline only rather than as absolute data.

The absolute values of resonant frequencies are important relative to expected excitation frequencies and the potential for magnification associated with a coincidence, or near coincidence of excitation and resonant frequencies. This is particularly impcrtant for internal excitation sources such as rotating machinery. However, for excitaticn induced by ground motion, the wavelength of the excitation is of equal importance.

The Rayleigh wave is the most significant disturbance on the surface of an elastic half-space and, therefore, is of primary concern for foundations on or near the surface of the earth. The Rayleigh wave velocity $V_{R}$ can be approximated as $V_{R} \approx 0.9 V_{S}$. The Rayleigh wavelength $\lambda_{R}$ is frequency dependent and is given by

$$
\lambda_{R}=V_{R} / f .
$$

The ability of a basemat structure to respond to ground motion in the form of a Rayleigh wave will be dependent on the Rayleigh wavelength relative to the plan dimensions of the basemat. This is illustrated in Fig. 7 where a basemat of equivalent diameter $D_{e}$ is assumed. It is obvious from Fig. $7 \mathrm{a}$ that if $\lambda_{R}>D_{e}$ the basemat will simply follow the motion of the ground with the potential for amplification of that motion if the system damping is relatively low and the ground motion frequency approximates a resonant frequericy of the soil-basemat system. On the other hand, as illustrated in Fig. $5 b$, with $\lambda_{R}<D_{e}$ the basemat will not respond to relatively high frequency (short wavelength) ground motion, as positive and negative ground displacements acting over the large surface area of the basemat will tend to integrate out or to cancel. There is obviously a "gray area" in the neighborhood of $\lambda_{R}=D_{e}$ for which positive statements regarding the response of the basemat cannot be made. 
In Table 8, Rayleigh wavelength and the raitio of wavelength to basemat width for each of the two APS foundations are tabulated as function of frequency.

Based on the above discussion, it is reasonable to conclude that ground motion is not of concern for frequencies corresponding to wavelengths less than one-half the width of the APS basemat, i.e., frequencies greater than $\left(2 V_{R} / W\right)$. Also, excitation/response frequencies less than $20 \mathrm{~Hz}$ are not of concern as beam deviations caused by magret vibrations can be corrected by the APS control systems.

It follows then that, relative to the ability to (a) control beam deviations and (b) respond to Rayleigh wave excitation, for APS-1, the ground motion frequencies of potential concern are in the range 20 to 38 $\mathrm{Hz}$, while for APS-2, the frequencies of potential concern are in the range 20 to $69 \mathrm{~Hz}$. Consequently, one would ideally like to design the APS basemats (i.e., select dimensions, masses, and mass moments of inertia) to ensure that system resonant frequencies are not in these frequency ranges of concern. In this regard it must be kept in mind that the frequency response curves in the vicinity of a resonant frequency can have significant width by virtue of the high damping values associated with soil-foundation interaction (see Fig. 4) and, therefore, these frequency ranges should be extended on either "end" to avoid magnification.

Relative to excitation from ground motion, the vertical, rocking, and coupled rocking/sliding modes are the vibration modes of concern. If we accept the results of this analysis, we observe, from Table 3 , that the calculated, "uncorrected" natural frequencies for these modes for the APS-1 foundation (40.1, 70.2, and $34.7 / 70.2 \mathrm{~Hz}$, respectively) are equal to or above the highest frequency of concern, viz., $34 \mathrm{~Hz}$, and the current design can be considered acceptable. A caveat here is that the calculated frequencies appear to be consistently high relative to actual frequencies based on comparisons with test data from experiments with large foundations (see Table 6). Accounting for damping as it affects resonant frequency would reduce the frequency at which peak amplitude occurs. Also, incorporation of the correction factor for frequency dependence of the stiffness coefficient, as given in Table 4, would significantly reduce the natural frequency.

For APS-2, the natural frequency for the "uncorrected" vertical vibration mode frequency $(20 \mathrm{~Hz})$ is the same as the lower bound frequency of $20 \mathrm{~Hz}$. In addition, the rocking mode frequency of $27.6 \mathrm{~Hz}$ and 
the higher of the two coupled rocking/sliding mode irequencies, $33.4 \mathrm{~Hz}$, are in the "range of concern".

Here, it should be noted that application of the frequency correction factor, which served to improve the agreement between theory and test results for the case stidies, w-uld reduce the natural frequencies of both the APS-1 and APS-2 foundations to values that are below the lower bounds of the ranges of concern. Corrections of the magnitude calculated for the large foundations of the case studies (see Table 6) would result in frequencies that are closer to the lower bound but still within the range of concern.

It remains to determine the possible amplification of ground motion for those modes of concern. This, in turn, requires calculating or assuming damping factors. As given in Table 3 and discussed above, calculated damping factors are large and either amplification is precluded or is modest $(<10 \%)$. However, the case studies of large foundations for which test results are available lead one to conclude that predicted damping is typically high by as much as a factor of 3 . Consequently, it may be more realistic to assume a damping factor based on experience from measurements on similar large foundations.

As given in Table 6 , measured vaiues of damping factor $D$ from tests on large foundations, ranged from 0.08 to 0.40 with an averaged value of 0.20 . From Fig. 6 , it can be determined that within the measured range of damping factor $(0.08$ to 0.40$)$, the magnification factor varies from 6 to 1.4 and the resonant frequency from 0.99 to 0.82 times the undamped natural frequency. For the APS foundations, which have equivalent radii larger than the equivalent radii for the tus: case studies, the damping factors can be expected to be greater. Considering this, an assumption of a damping factor of $0.2\left(Q=2.55, f_{r}=0.96 f_{n}\right)$ for the APS foundations would seem reasonable.

Future studies will include consideration of (1) the application of the impedance function approach as a means to more accurately account for frequency dependence of the spring and damping coefficients, (2) means to account for the finite flexural rigidity of the APS basemats, and (3) applisation of a finite element code (FLUSH) to provide a further basis for the evaluation of the equivalent lumped parameter modeling. 


\section{Acknowledgments}

The author gratefully acknowledges the helpful discussions and contributions provided by his colleagues M. G. Srinivasan, S. S. Chen, and J. Wong at Argonne. Professor F. E. Richart, Jr., consultant to the 7-GeV Advanced Photon Source Project, also reviewed the manuscript and provided useful comments and suggestions. 


\section{References}

Gazetas, G., 1983, "Analysis of Machine Foundation Vibrations: State of the Art Review", Soil Dynamics and Earthquake Engineering, Vol. 2, No. 1, pp. $2 \cdot 42$

Iguchi, M., Akino, K., Jido, J., Kawamura, S., Ishikawa, Y., and Nakata, M., 1988, "Large-Scale Model Tests on Soil-Reactor Building; Part 1: Forced Vibration Tests", 9th W.C.E.E. - World Conference on Earthquake Engineering. August 8, 1988, Kyoto, Japan

Ishida, K., 1985, "Dynamic Characteristics of Soil-Foundation Interaction System Detected from Forced Vibration Test and Earthquake Observation", Earthquake Engineering and Structural Dynamics, Vol. 13, 799-825

Richart, F. E., Jr., and Whitman, R. V., 1967, "Comparison of Footing Vibration Tests with Theory", J. Soil Mech. Fdn. Engrg. Div.

Richart, F. E., Jr., Hall, J. R., Jr., and Woods, R. D., 1970, "Vibrations of Soils and Foundations", Prentice-Hall, Inc., Englewood Cliffs, NJ

Richart, F. E., Jr., 1987, Personal Communication

Richart, F. E., Jr., 1988, Personal Communication

Richart, F. E., Jr., 1989, "Foundation Dynamics - 1987", The Art and Science of Geotechnical Engineering - At the Dawn of the Twenty-First Century: A Volume Honoring Ralph B. Peck, ed. by E. J. Cording et al, Prentice-Hall, Englewood Cliffs, NJ, pp 31-54

Srinivasan, M. G., Kot, C. A., and Hsieh, B. J., 1989, "Determination of Soil Impedance Functions from Vibration-Test Response of a Circular Foundation," (Submitted for publication to Int'l J. for Soil Dynamics and Earthquake Engrg)

STS Consultants, 1988, "Subsurface Exploration and Geotechnical Engineering Evaluation - Proposed 7-GeV Advanced Photon Source (APS)", Final Report, Vols. 1 and 2, STS Consultants, Northbrook, IL 


\begin{tabular}{|c|c|c|c|c|}
\hline \multicolumn{5}{|c|}{$\begin{array}{l}\text { Table 1.* Spring and Damping Coefficients for Rigid } \\
\text { Circular Foundation Resting on Eldstic } \\
\text { Half-Space }\end{array}$} \\
\hline $\begin{array}{l}\text { Mode of } \\
\text { Vibration }\end{array}$ & $\begin{array}{l}\text { Spring } \\
\text { Coeff. } k\end{array}$ & $\begin{array}{r}\text { Danping } \\
\text { Coef } \overline{\bar{Y}} . \quad \mathrm{C}\end{array}$ & $\operatorname{Mass}_{B}$ & $\begin{array}{l}\text { Damping Ritio } \\
D=\frac{c}{2 \sqrt{k m}}\end{array}$ \\
\hline Vertical ( $z$ ) & $\frac{4 G I_{0}}{I-\nu}$ & $\frac{3.4 r_{0}^{2}}{1-\nu} \sqrt{2 G}$ & $\frac{1-\nu}{4} \frac{m}{\rho r} 3$ & $\frac{0.425}{\sqrt{B_{2}}}$ \\
\hline Sliding $(x)$ & $\frac{8}{2-2} G I_{0}$ & $\frac{4.6}{2-2} r_{0}^{2} \sqrt{D G}$ & $\frac{2-z}{8} \frac{m}{\rho r_{0}}$ & $\frac{0.288}{\sqrt{B_{x}}}$ \\
\hline Rocking $(\psi)$ & $\frac{8 G r_{0}^{3}}{3(1-\nu)}$ & $\frac{0.8 \Sigma_{0}^{4} \sqrt{p G}}{(1-\nu)\left(1+3_{\psi}\right)}$ & $\frac{3(1-\nu)}{8} \frac{I_{\psi}}{p r_{0}}$ & $\frac{0.15}{\left(1+B_{\psi}\right) \sqrt{B_{\psi}}}$ \\
\hline Torsional $(\theta)$ & $\frac{16 G r_{0}^{3}}{3}$ & $\frac{r_{0}^{4} \sqrt[4]{\left(B_{\theta} \rho G\right) / 3}}{1+2 B_{\theta}}$ & $\frac{I_{\theta}}{\rho r_{0}}$ & $\frac{0.50}{1+29 \theta}$ \\
\hline
\end{tabular}

In Table 1 , see Richart, Hall, and Woods, $19 \%$, ro is the radius of the circular foundation, $m$ is the mass of the foundation, and $G, \nu$, and $p$ are the shear modulus, poisson's ratio, and mass density $(\mu / g)$ of the elastic half-space.

In order to use the above expressions for the case of rigid rectangular foundations of width, $b$, and length, $L$, an equivalent circular radius can be calculated from

$$
\begin{aligned}
& r_{0}=\left[\frac{b L}{\pi}\right]^{1 / 2} \text { for Translation (Vertical or sliding), } \\
& r_{0}=\left[\frac{b L^{3}}{3 \pi}\right]^{1 / 4} \begin{array}{l}
\text { for Rocking about a horizontal axis at } \\
\text { mid-length of the base, and }
\end{array} \\
& r_{0}=\left[\frac{b L\left(b^{2}+L^{2}\right)}{6 \pi}\right]^{1 / 4} \begin{array}{l}
\text { for Torsional Motion about a ver- } \\
\text { tical axis through the centroid of } \\
\text { the base. }
\end{array}
\end{aligned}
$$

*Ref. Richart, 1939 


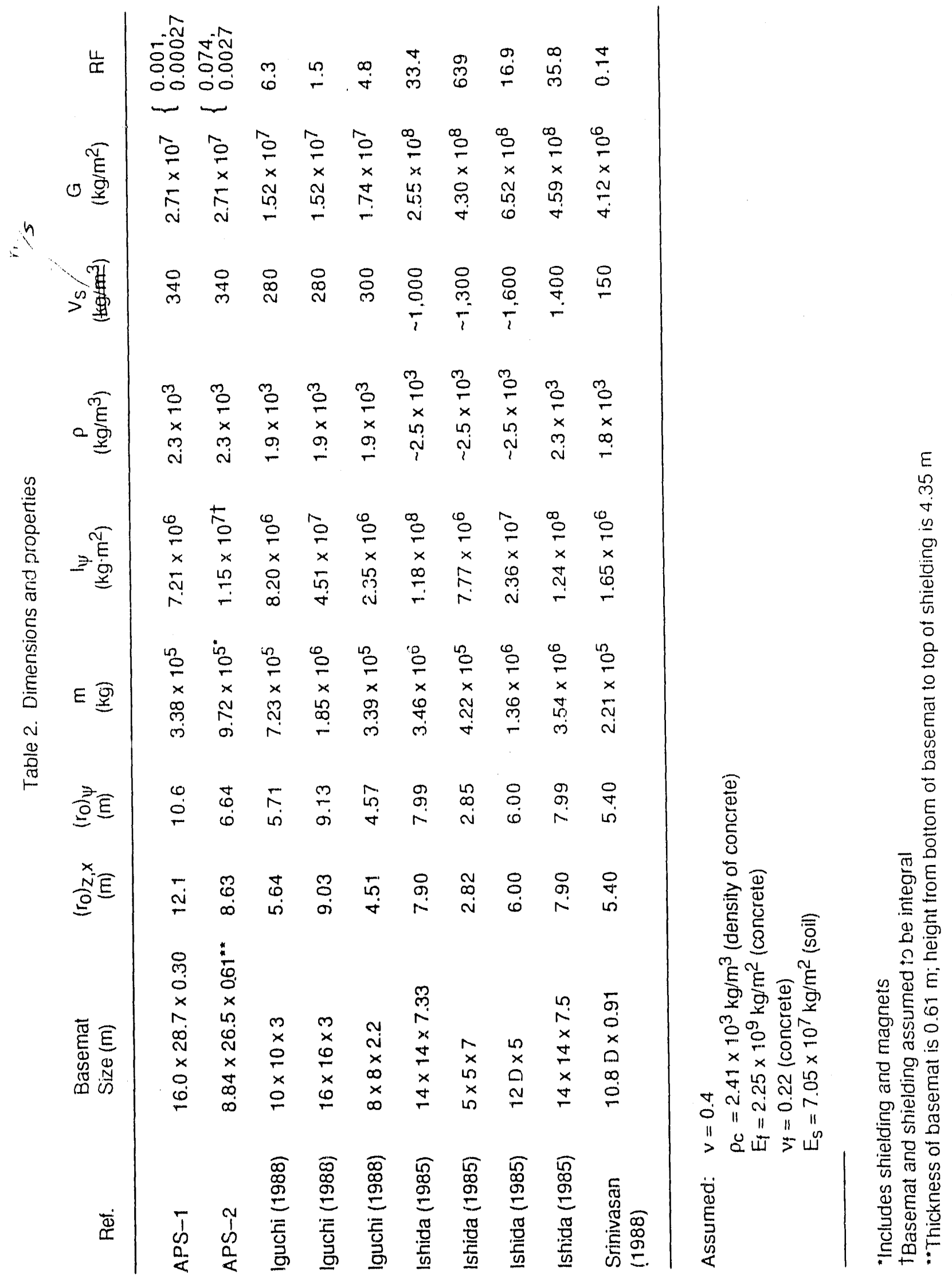




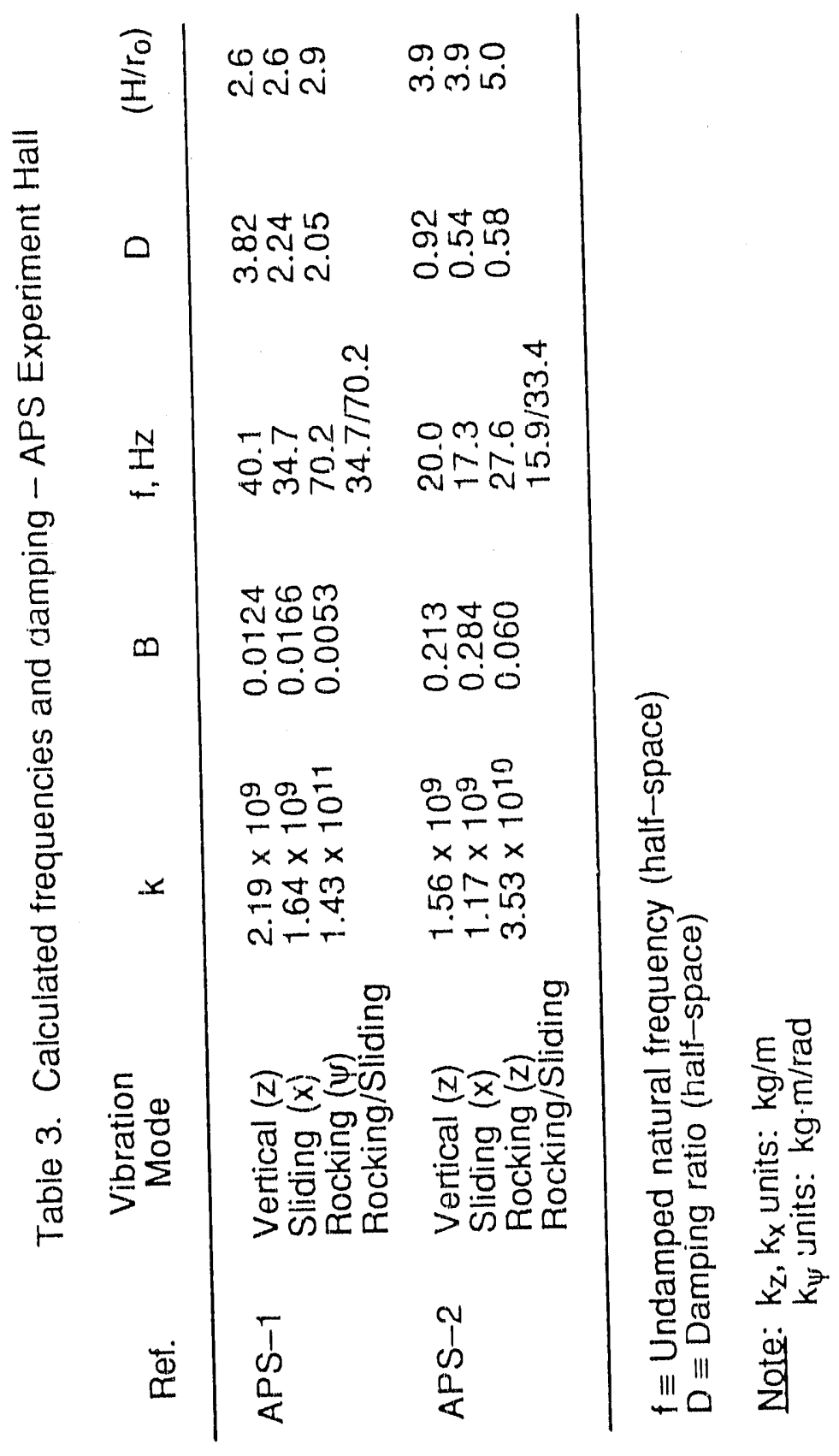




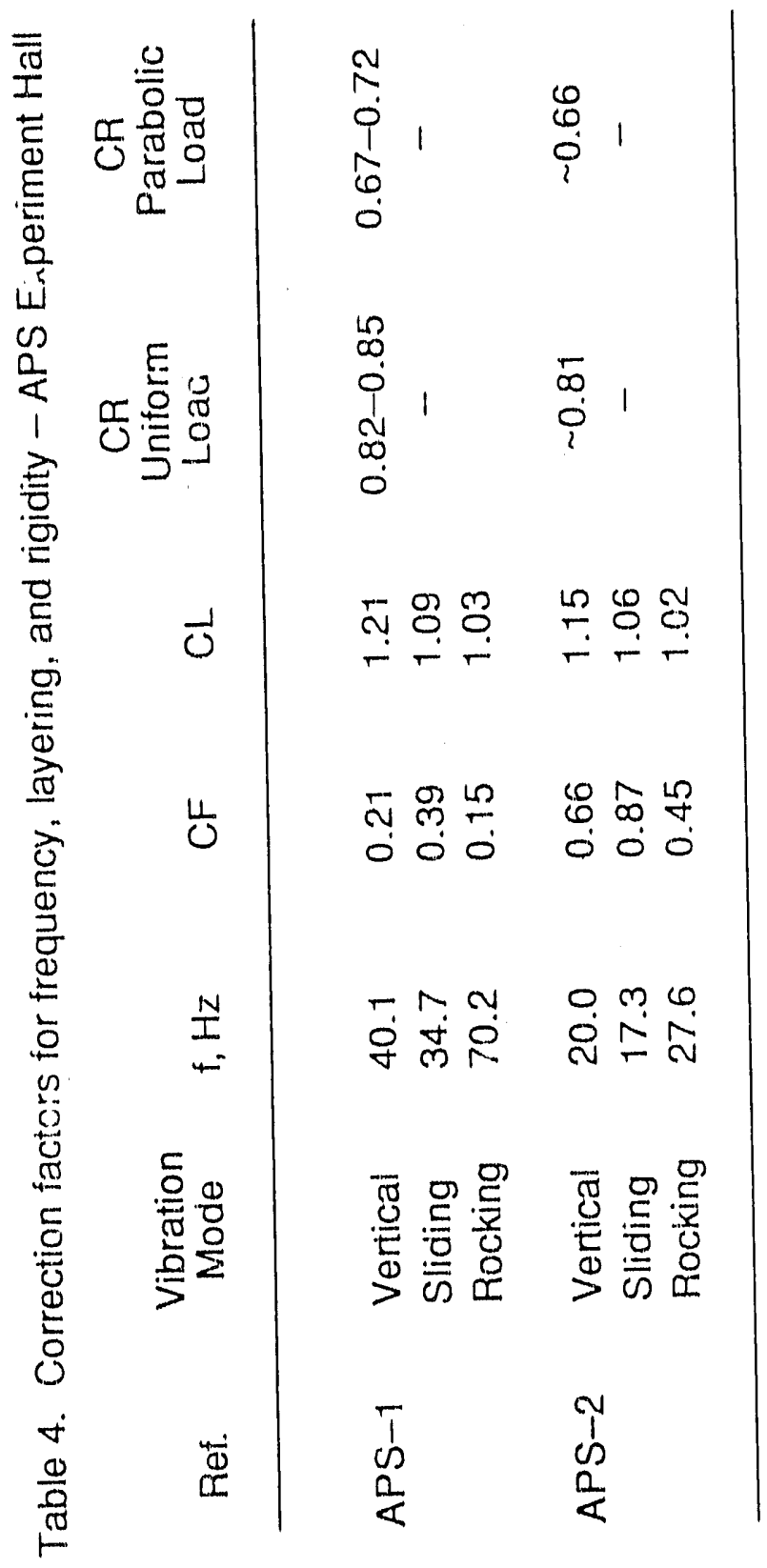


Table 5." Damping coefficlents for vertical motion of foundation on elastic layer over rigid base

\begin{tabular}{lcc}
$\left(H / r_{\theta}\right)$ & $\left(C_{Z L} / C_{Z}\right)$ & $\left(D_{Z L} / D_{Z}\right)$ \\
\hline 1 & 0.066 & 0.044 \\
2 & 0.11 & 0.089 \\
3 & 0.19 & 0.16 \\
4 & 0.35 & 0.31 \\
. &. &. \\
$\infty$ & 1.0 &. \\
\hline
\end{tabular}

$H \equiv$ thickness of elastic layer

$r_{0} \equiv$ radlus of equivalent circular basemat

"Ref. Rictiart, 1989 


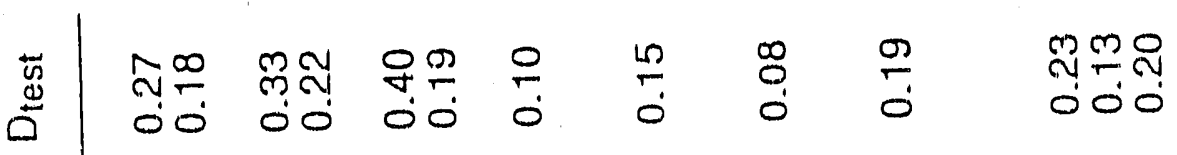

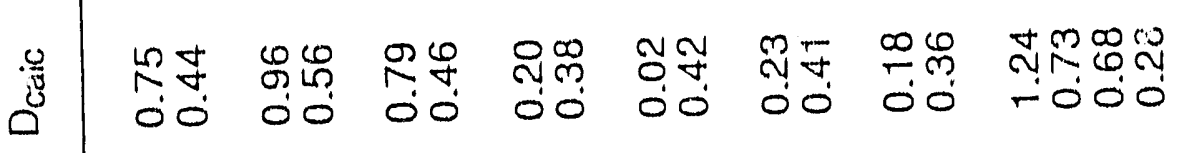

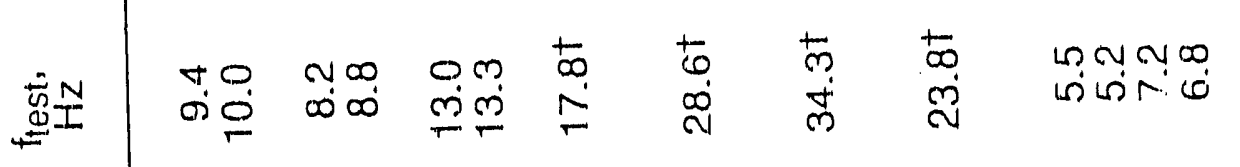

$$
\begin{aligned}
& \text { 旁 荡 }
\end{aligned}
$$

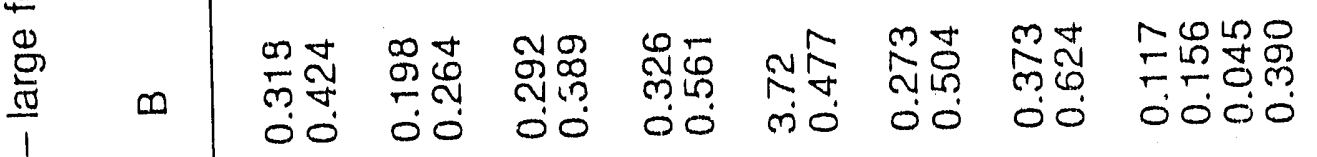

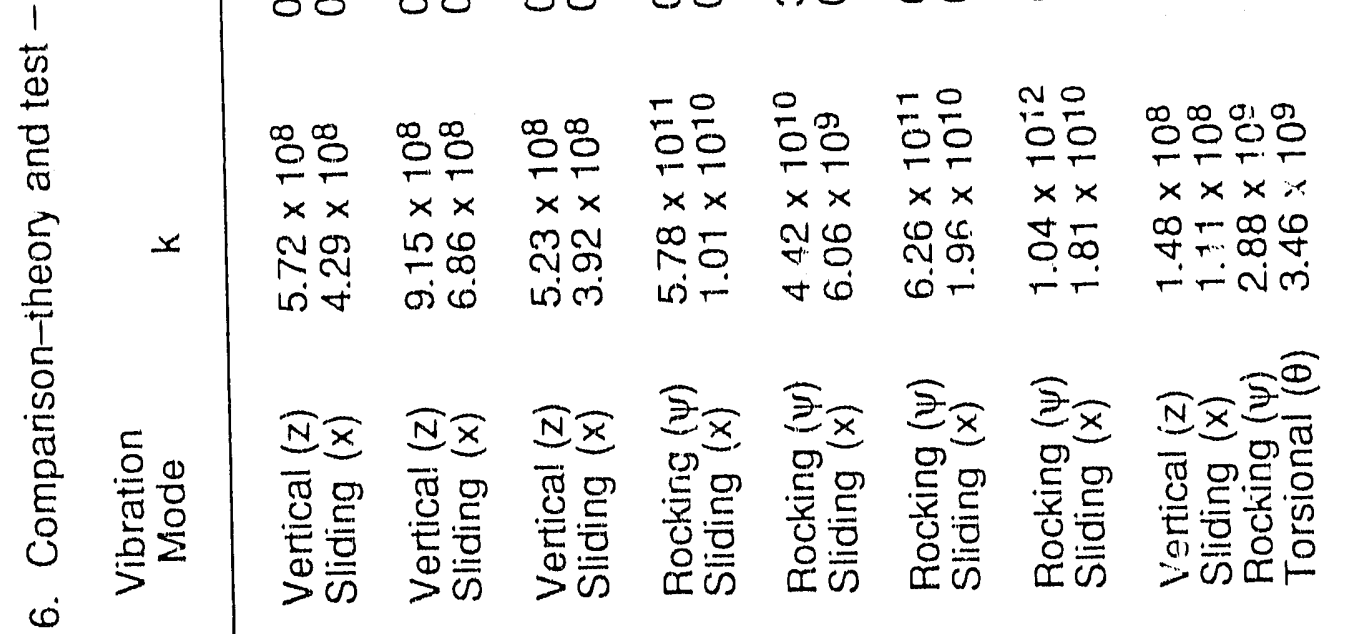

$$
\begin{aligned}
& \frac{\infty}{\frac{0}{0}}
\end{aligned}
$$

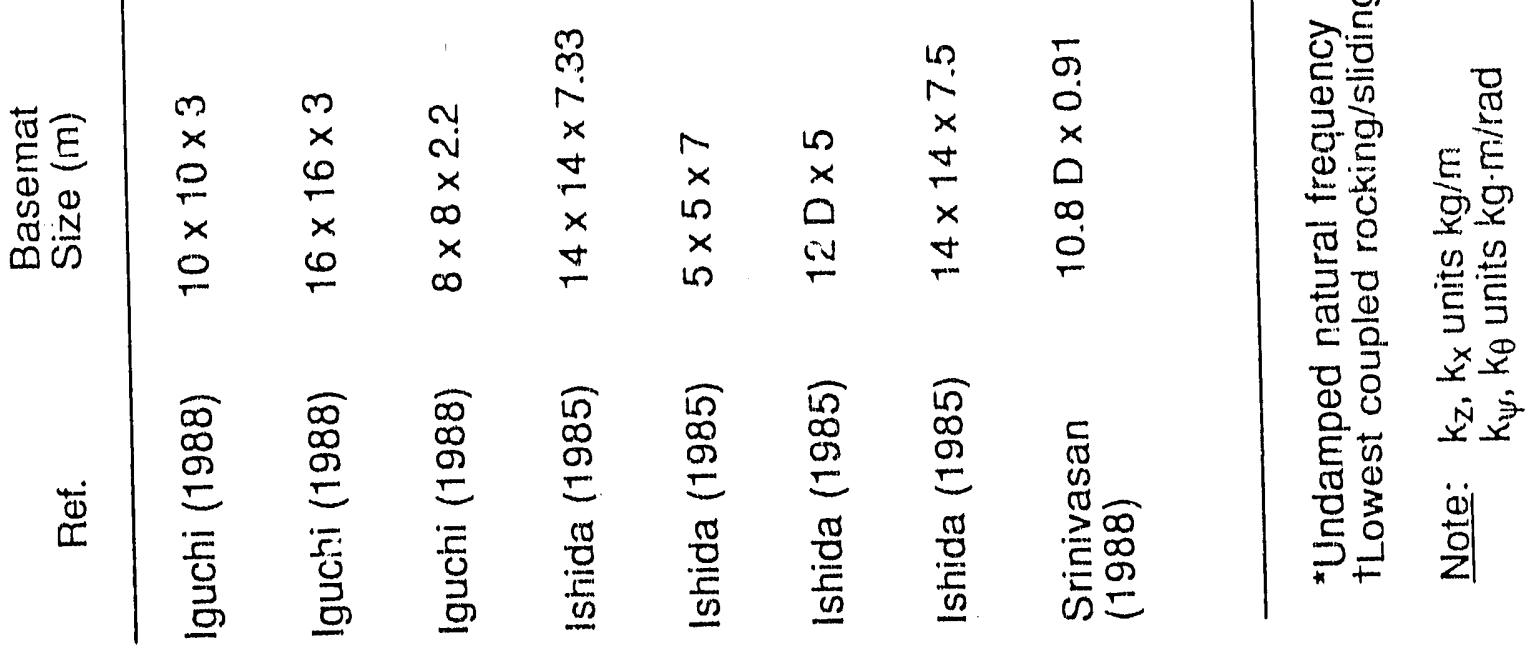




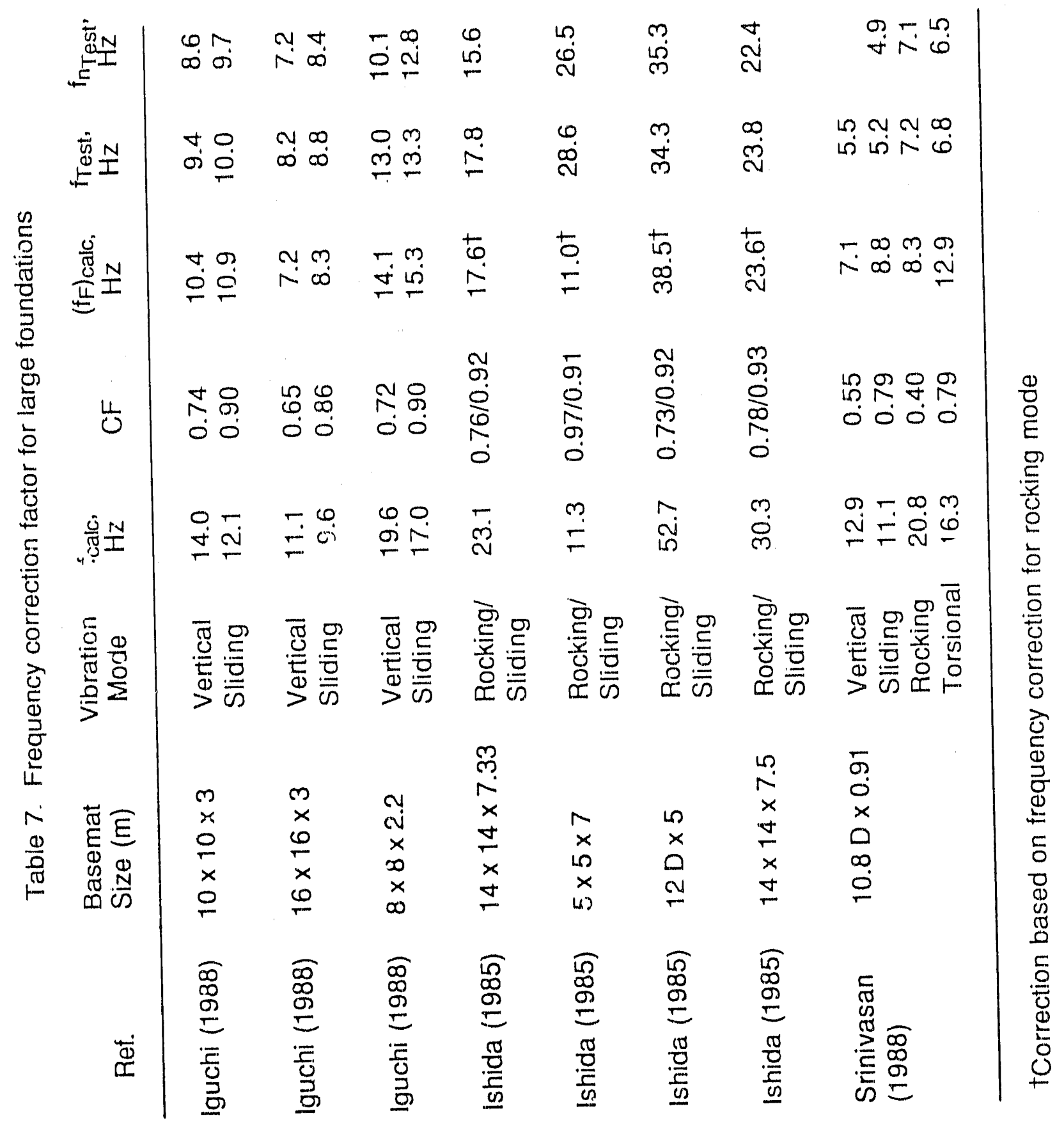


Table 8. Rayleigh wavelength vs. frequency

\begin{tabular}{cccc} 
& & \multicolumn{2}{c}{$\left(\lambda_{R} M\right)$} \\
\cline { 3 - 4 }$f_{1} \mathrm{~Hz}$ & $\lambda_{R, m}$ & APS-1 & APS-2 \\
\hline 5 & 61.2 & 3.8 & 6.9 \\
10 & 30.6 & 1.9 & 3.5 \\
15 & 20.4 & 1.3 & 2.3 \\
20 & 15.3 & 0.96 & 1.7 \\
25 & 12.2 & 0.76 & 1.4 \\
30 & 10.2 & 0.64 & 1.2 \\
40 & 7.6 & 0.48 & 0.86 \\
60 & 5.1 & 0.32 & 0.58 \\
\hline
\end{tabular}

$W \equiv$ Width of rectangular basemat

$W=16.0 \mathrm{~m}$ for APS-1

$W=8.84 \mathrm{~m}$ for APS -2

$V_{R}=0.9 V_{S}=306 \mathrm{~m} / \mathrm{s}$ 


\section{SOIL-STRUCTURE INTERACTION MODELS FOR EXPERIMENT} HALL BASE MAT -

Experiment Hall: Ring-shaped structure (cross-section shown in Fig. 2 ); basemat divided into 40 cells ( $9^{\circ}$ sectors) separated by expansion joints.

Consider a single cell ( $Q^{\circ}$ sector): The base mat supporting the storage ring magnets and shie!ding tunnel is 2 - $\mathrm{ft}$ thick; remainder of experiment hall base mat is $1-f t$ thick. The two parts are separted by an expansion joint.

Divide single cell basa mat into its iwo component parts: Ease mat supporting $S R$ magnets (2-ft thick part); main part (1-it thick part).

Define equivalent circular base mats

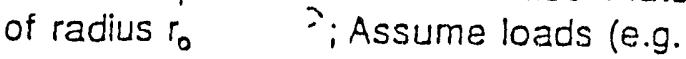
magnets and shielding) are uniformily distributed.

Establish lumped-parameter (massspring-dashpot) models for analysis of soil-structure interaction. (a)
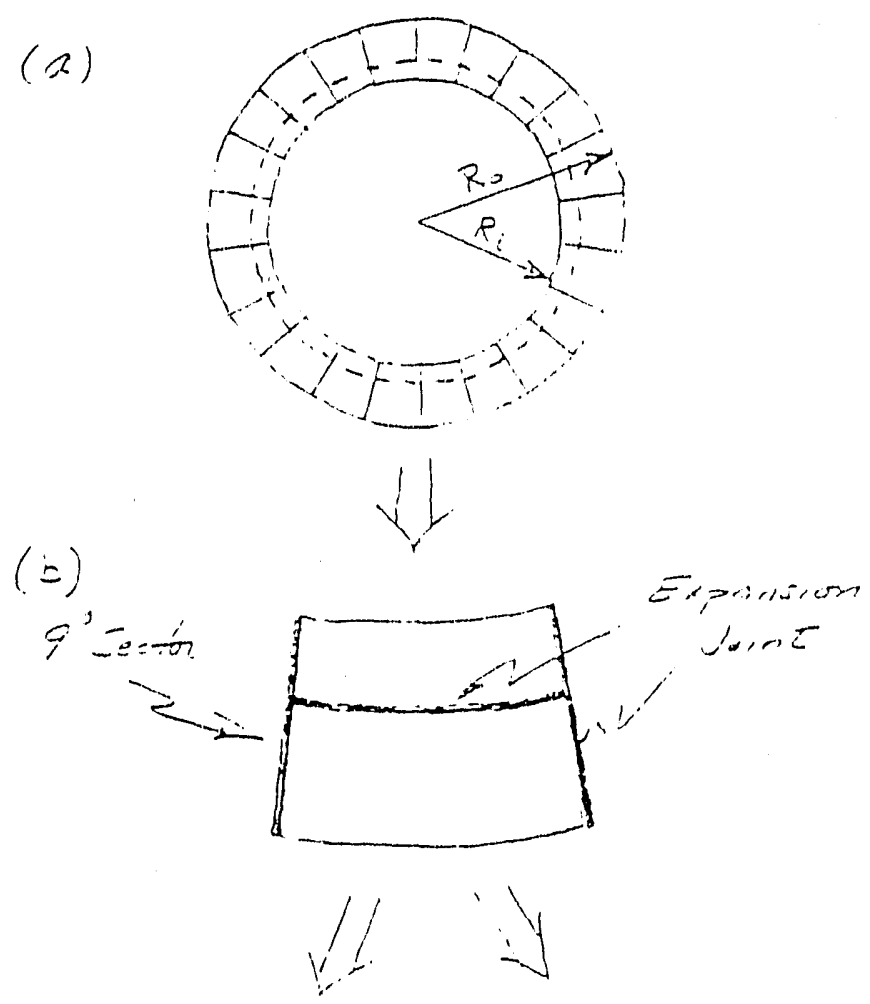

$(=j$
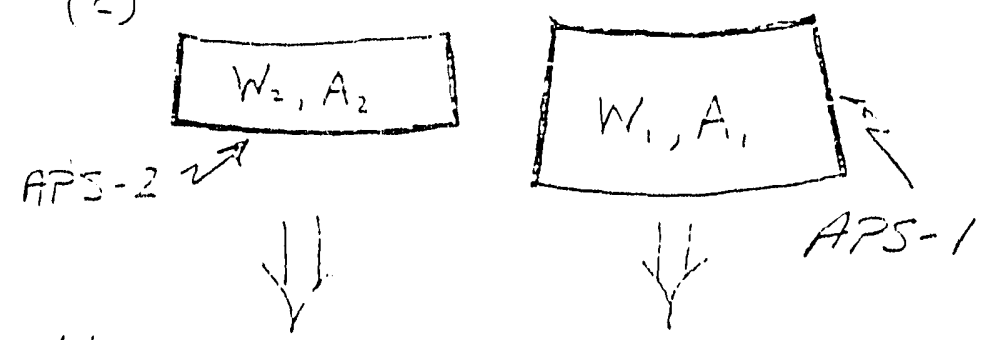

(d)

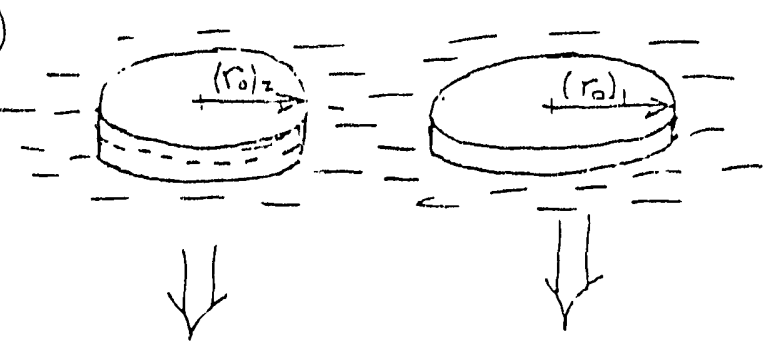

(e)
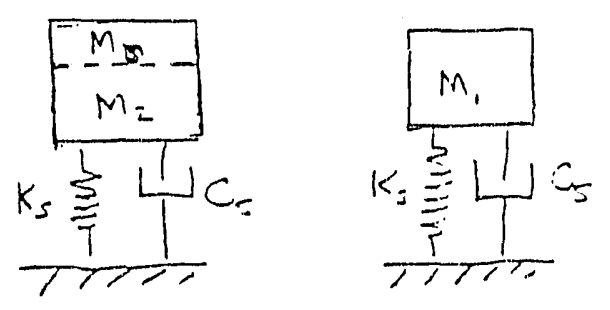


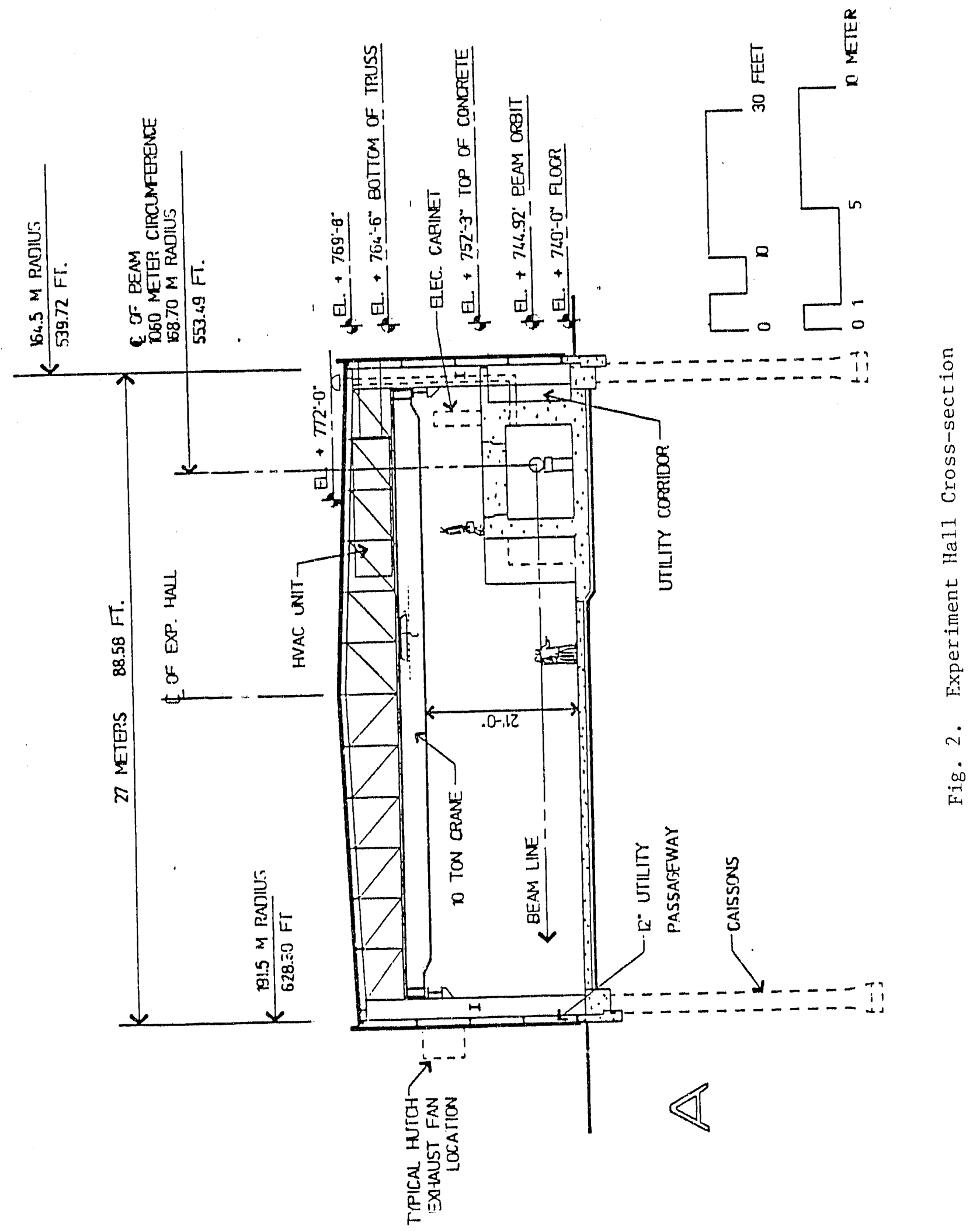




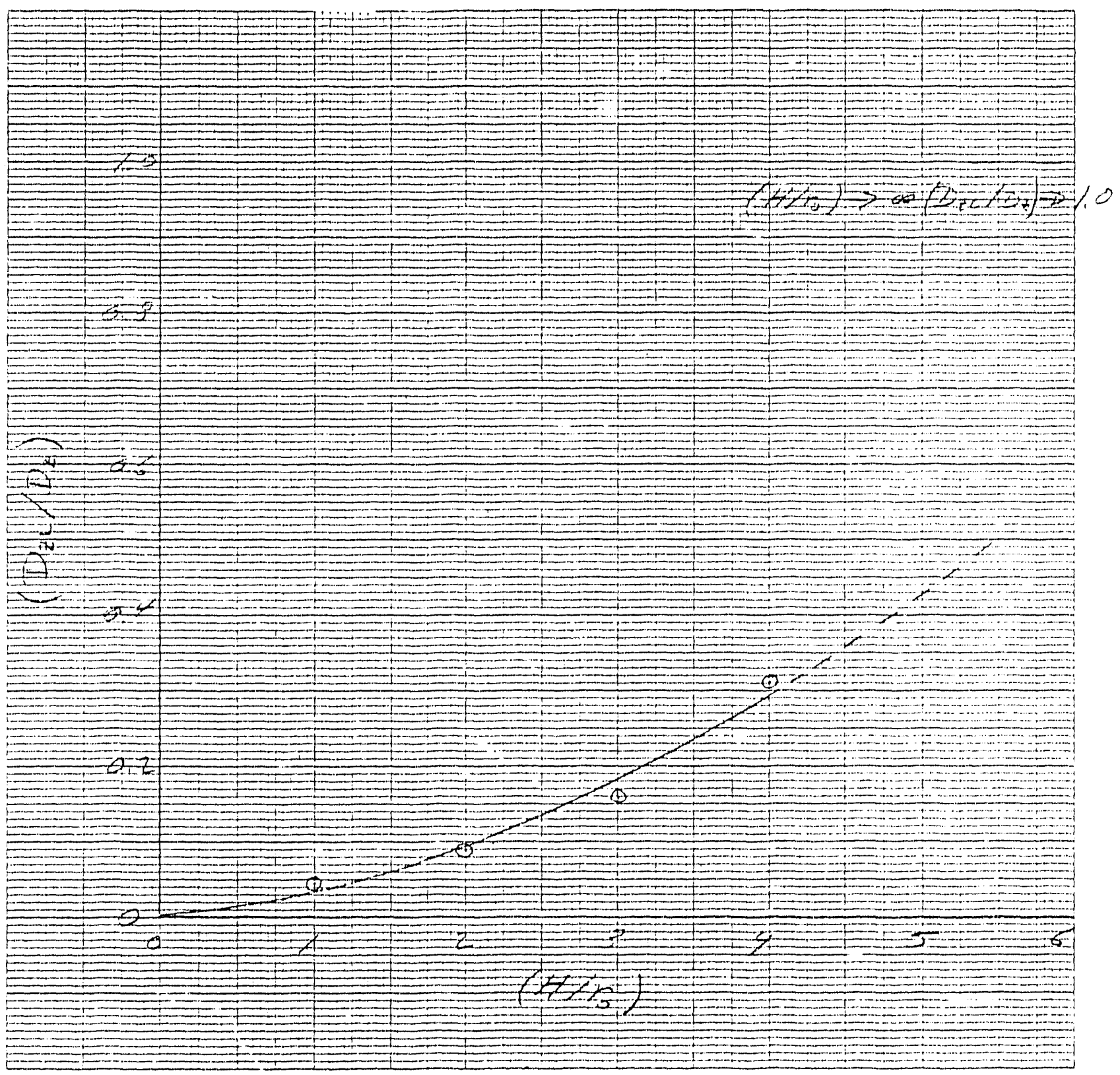

Fig. 3. Damping ratio for vertical vibration of foundation on elastic layer over rigid base 

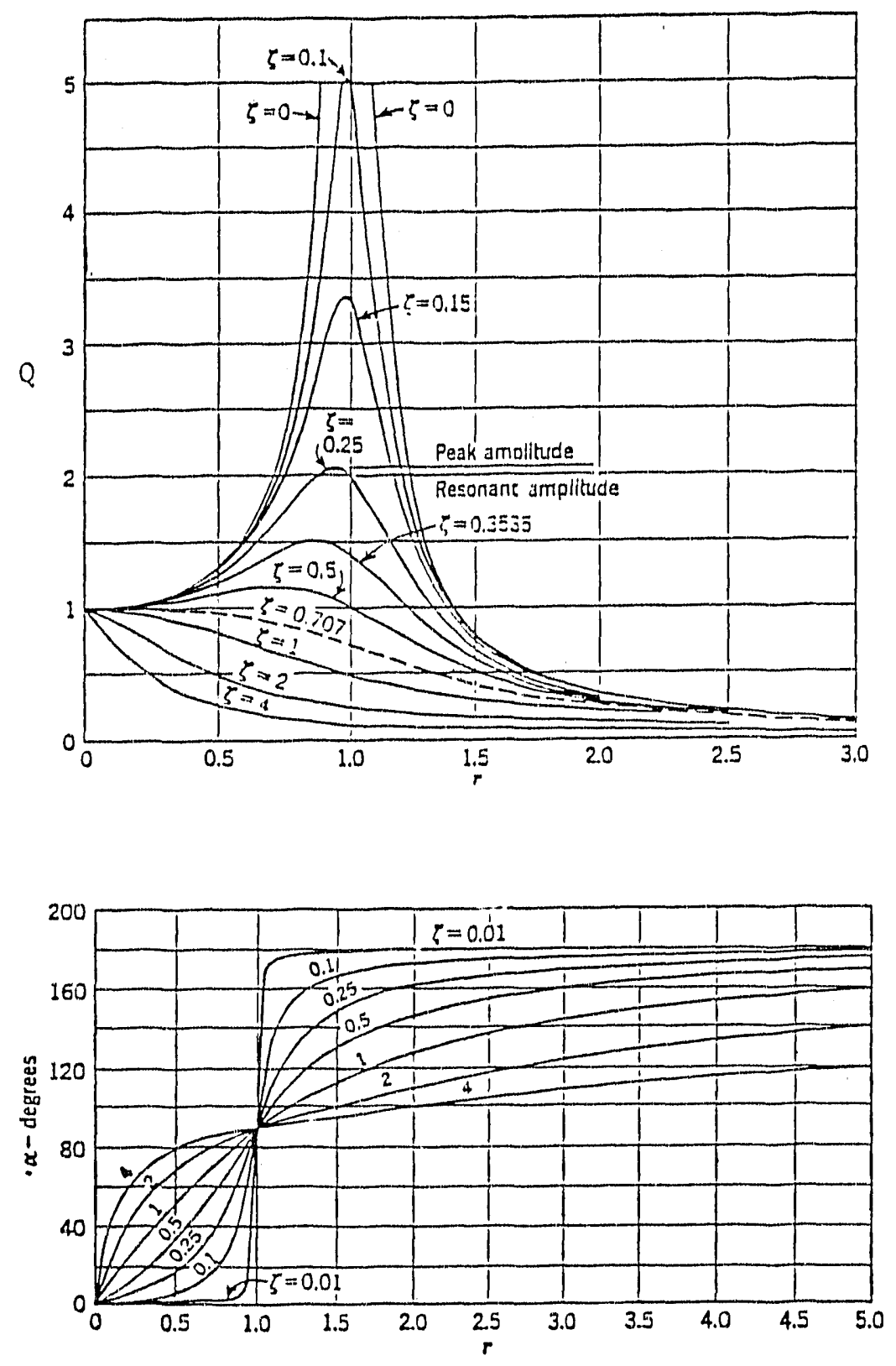

Fig. 4. Amplification factor ( $Q$ ) and phase angle $(\alpha)$ as a function of frequency ratio $(r)$ for a constant force excitation $\left(\zeta=D, r=f / f_{n}\right)$ 


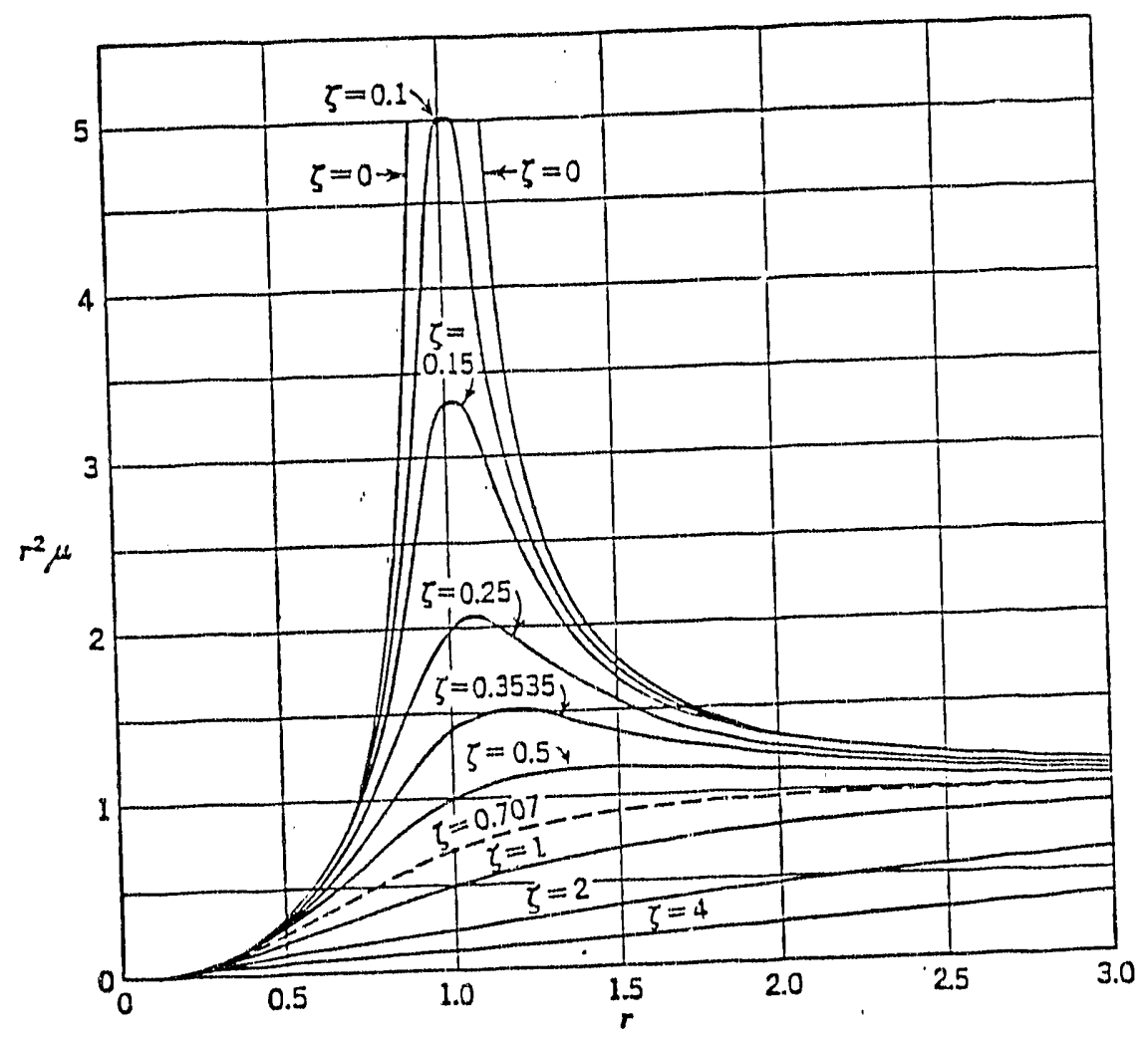

Fig. 5. Dimensionless amplitude ratio for a system with inertial driving force 


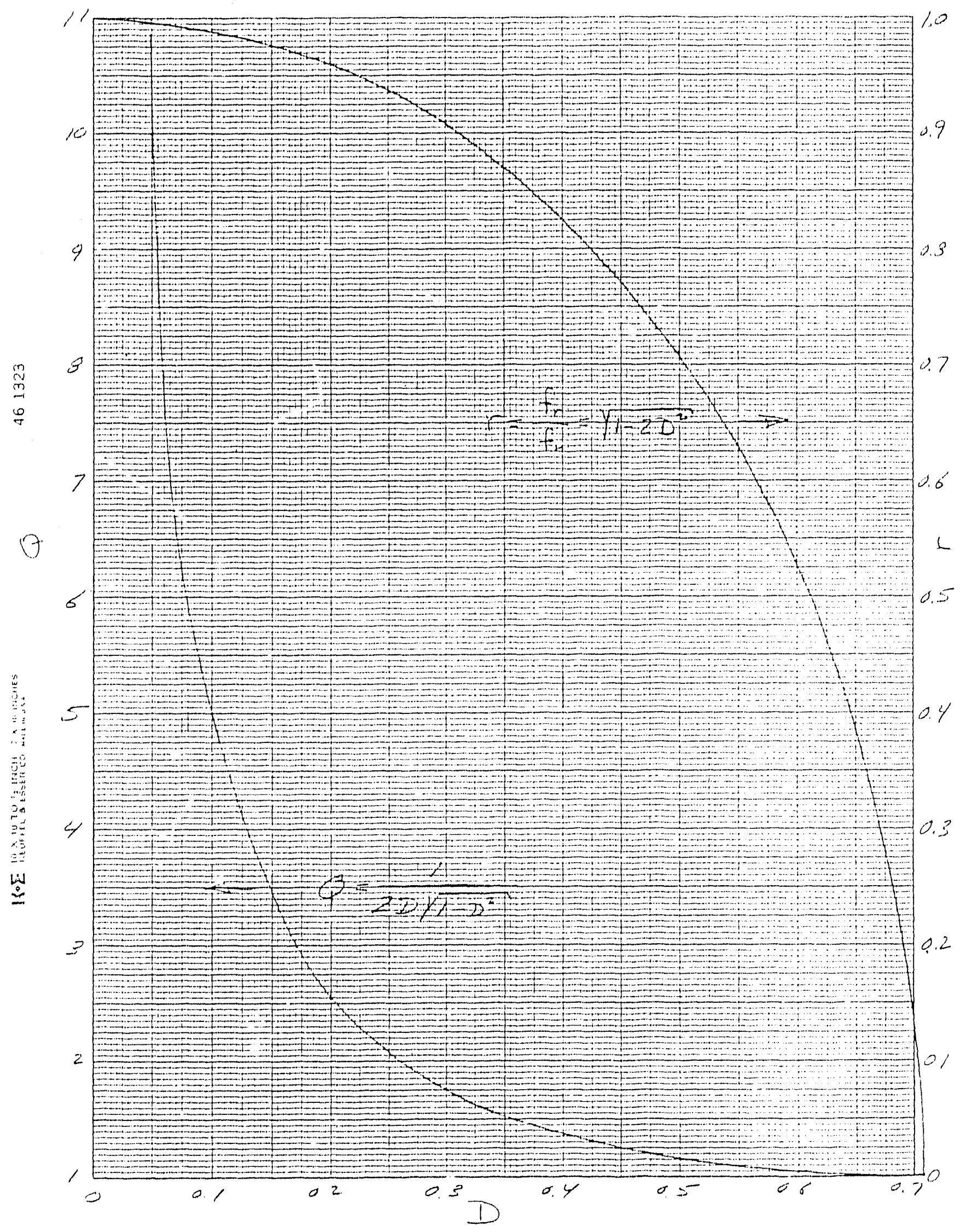

Fig. 6. Effect of damping on magnification factor and resonant frequency 

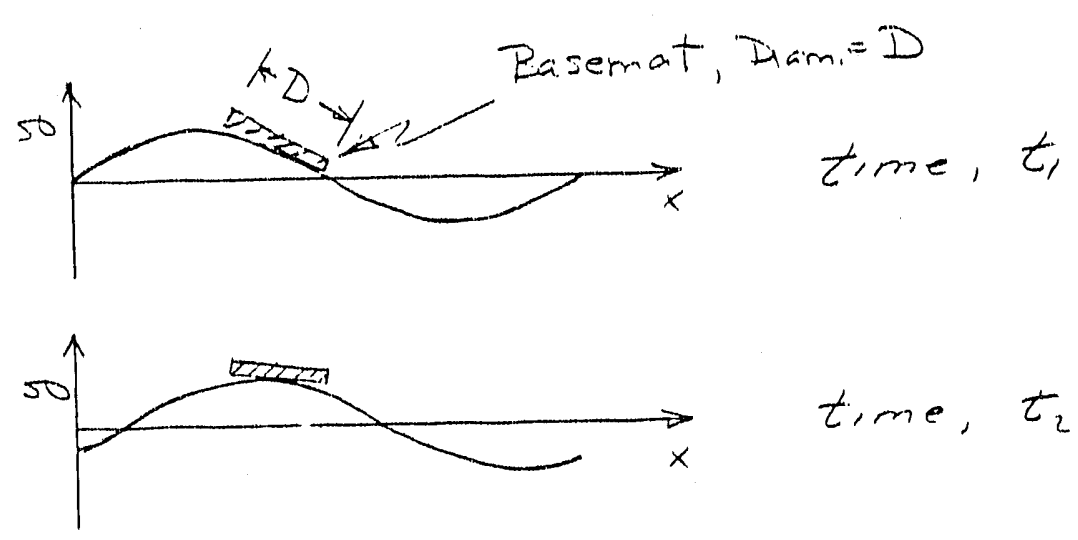

time, $t_{2}=t_{1}+0.1 T$

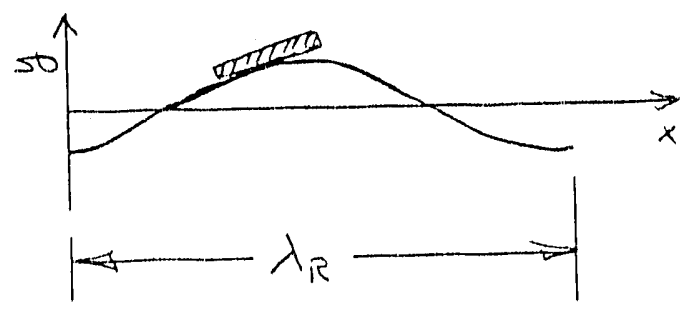

$$
\begin{aligned}
& \text { time, } t_{F}=t_{1}+02 T \\
& \lambda_{R}=S D \quad T=\frac{1}{f}=\frac{\lambda_{z}}{V_{1}}
\end{aligned}
$$

(a) $\lambda_{R}>D$
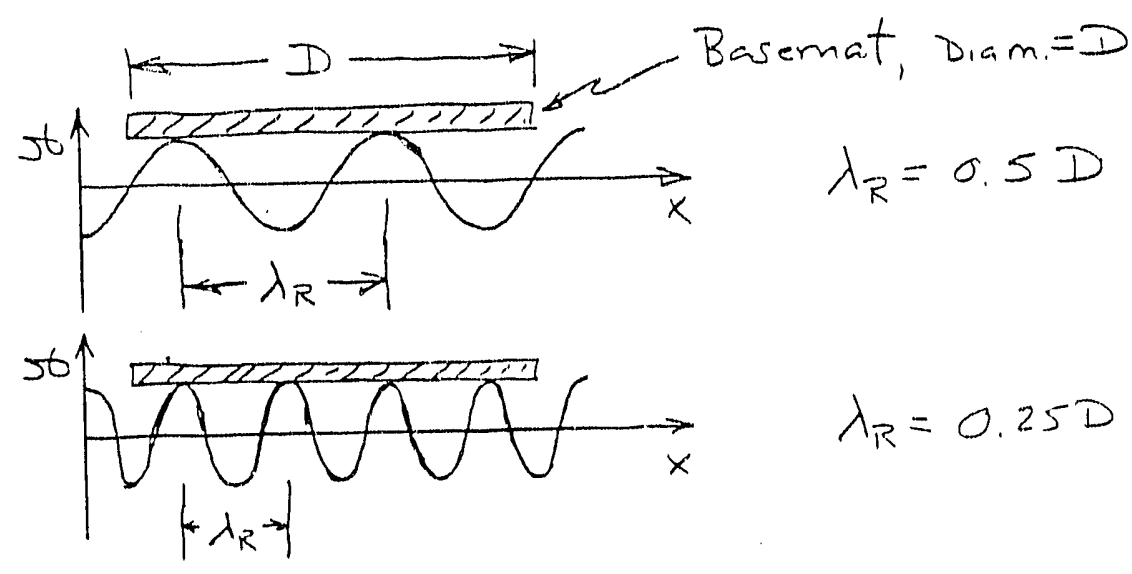

(b) $\lambda_{R}<D$

Fig. 7. Relationship between Rayleigh wavelength and dimension of baseman (a) $\lambda_{R}>D$; (b) $\lambda_{R}<D$ 


\title{
APPENDIX 1
}

\author{
A. Soil Profile from Borings \\ B. Crosshole Seismic Test Data
}




\section{A. Soll Profile*}

1. Fill materials were encountered at various locations along the proposed APS alignment. In general, this fill consists of silty clay.

2. Weathered till was encountered in all of the borings extending to depths ranging from 10 to $24 \mathrm{ft}$. The weathered till generally consists of brownish colored hard to very stiff silty clay.

3. Unweathered till was encountered underlying the weathered till. The unweathered till generally consists of gray silty clay or clayey silt containing traces of sand, gravel, and shale. The unweathered till has a relatively low plasticity and generally a very stiff to hard consistency.

4. Outwash deposits were encountered sporadically across the site. These outwash deposits generally consisted of sand and silt and occasionally gravel. The borings indicate these deposits to be relatively thin and discontinuous in nature.

5. Lemont drift was encountered underlying the unweathered till and extended to the bedrock surface. The Lemont drift was found to consist of a dense to extremely dense formation of sand, silt, and gravel and was usually saturated.

6. Bedrock was encountered underlying the Lemont drift and was found to consist of dolomitic limestone. 


\section{B. Crosshole Selsmic Tests}
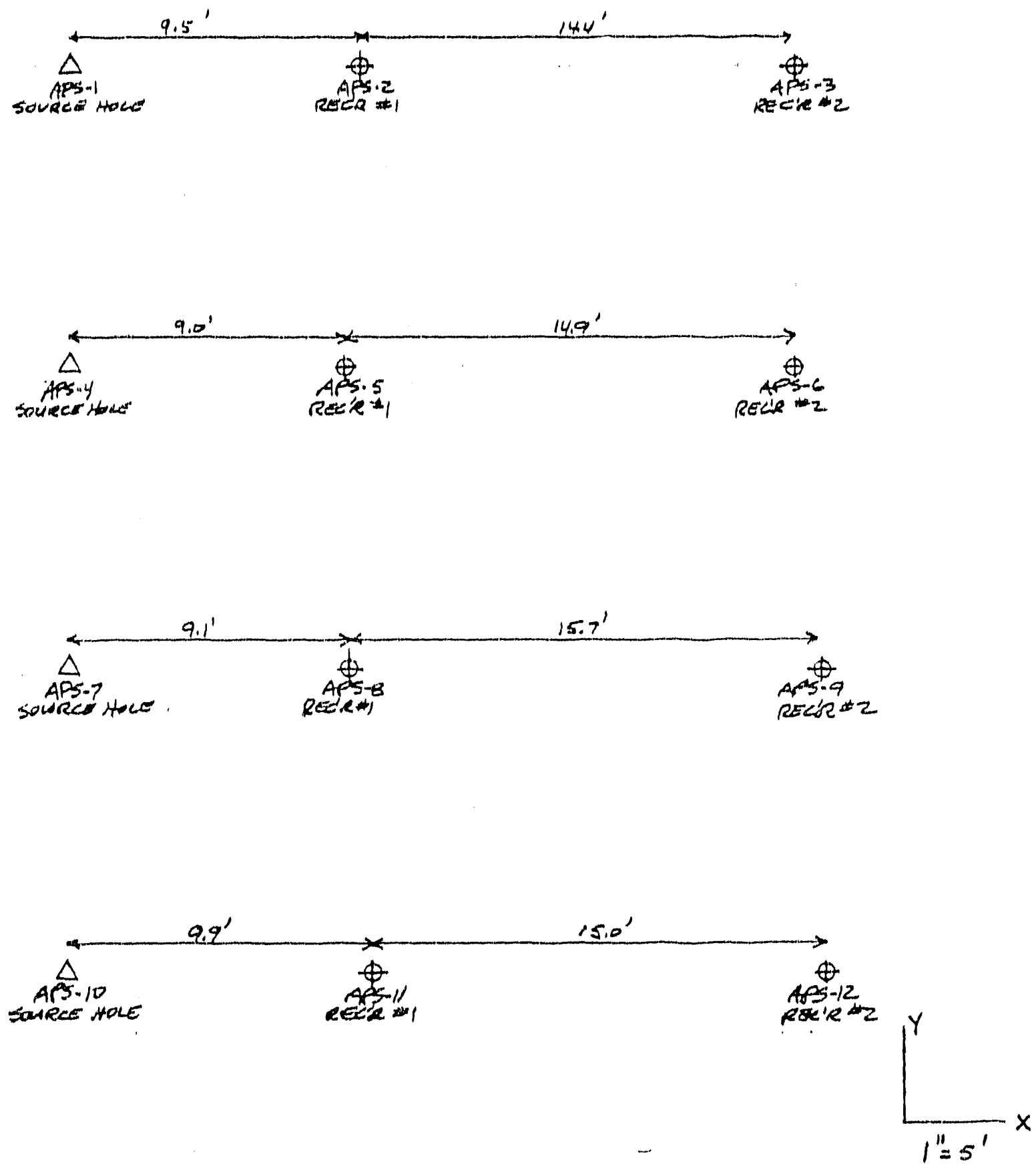

\begin{tabular}{|c|c|c|c|}
\hline & PRONCTNCUENT & Derawn ar & TROLesm \\
\hline & CROSSHOLE SEHSMK LOCATTON ALAN & CMECARD ar & \\
\hline 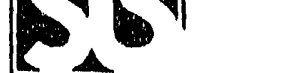 & APS - ARGONNE LABORATTRYY & Ampoves ar & \\
\hline & & $1^{\prime \prime \prime}=5^{\prime}$ & APGOARE \\
\hline Cormeutithes & & $\begin{array}{l}25229 \\
2529\end{array}$ & \\
\hline
\end{tabular}



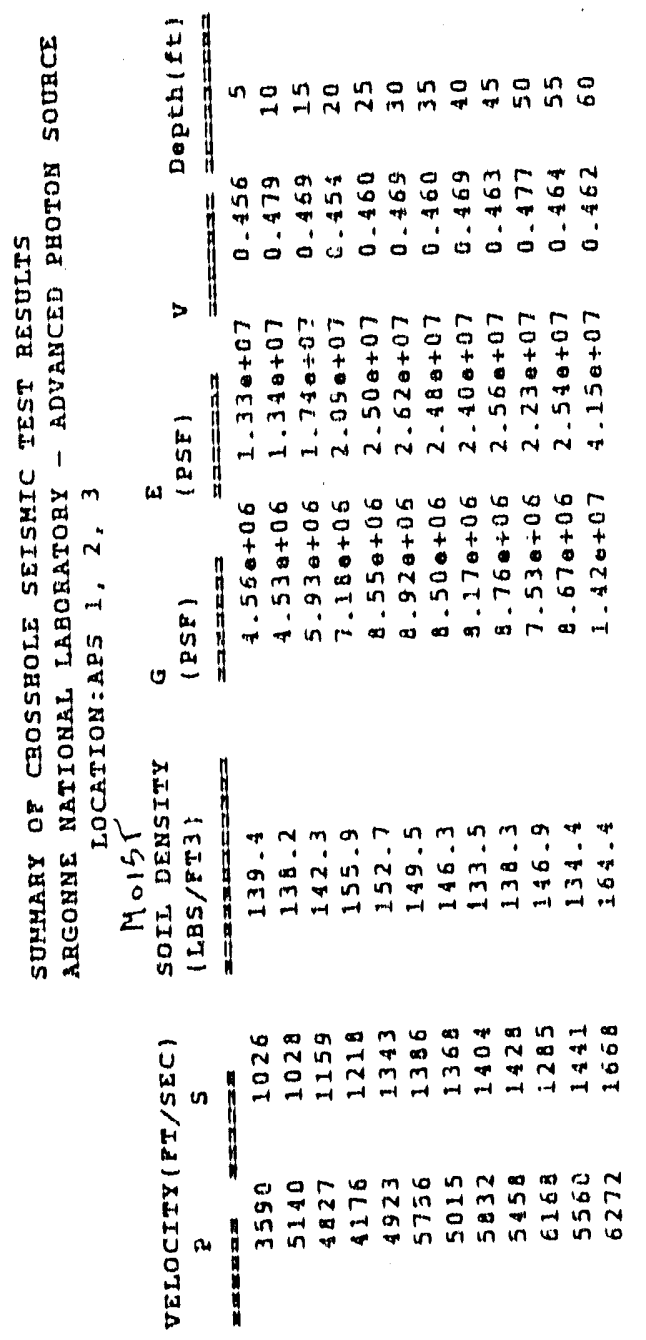

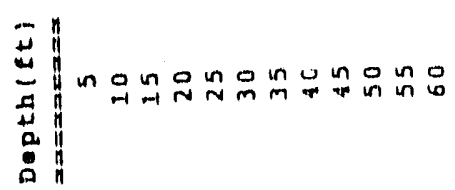

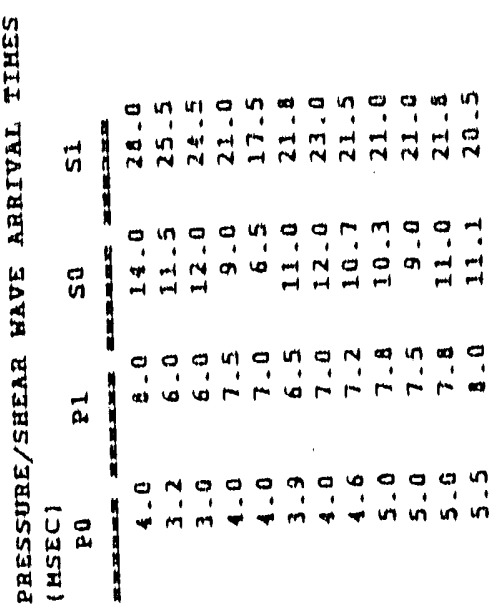

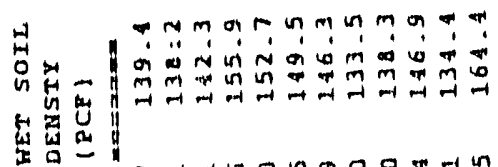
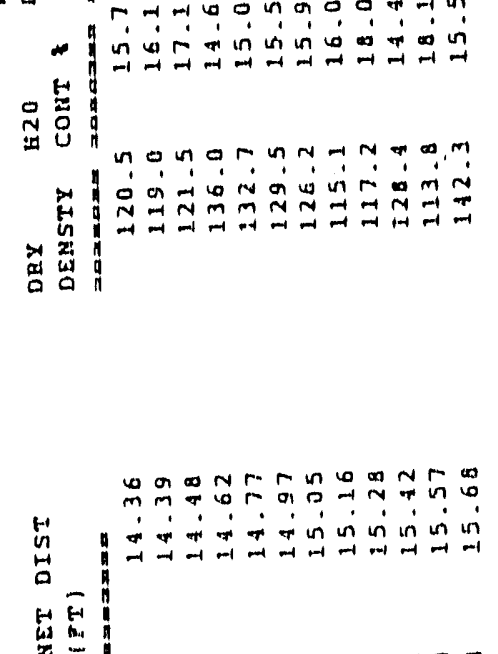

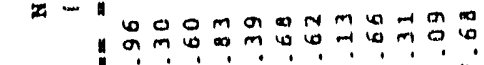

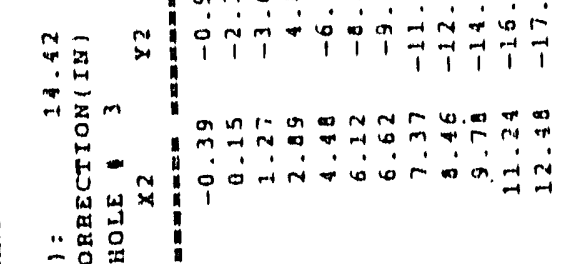

至

年

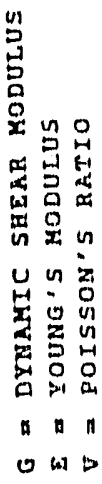




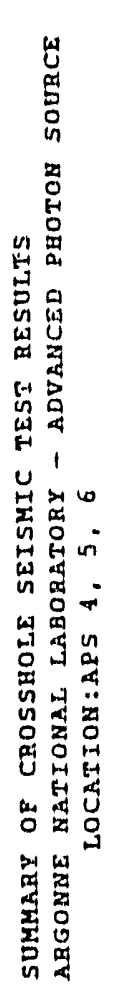

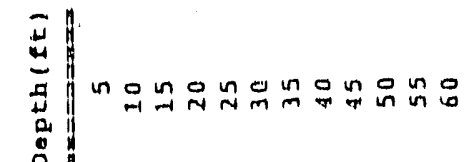

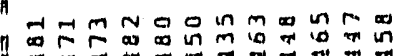

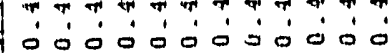
h 5N25

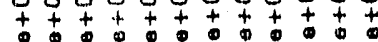
a

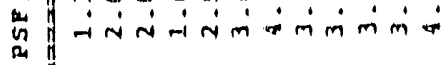
$\omega=$

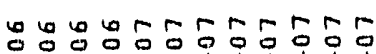

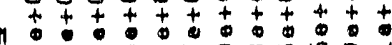

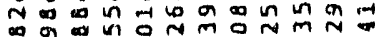
का 0 政
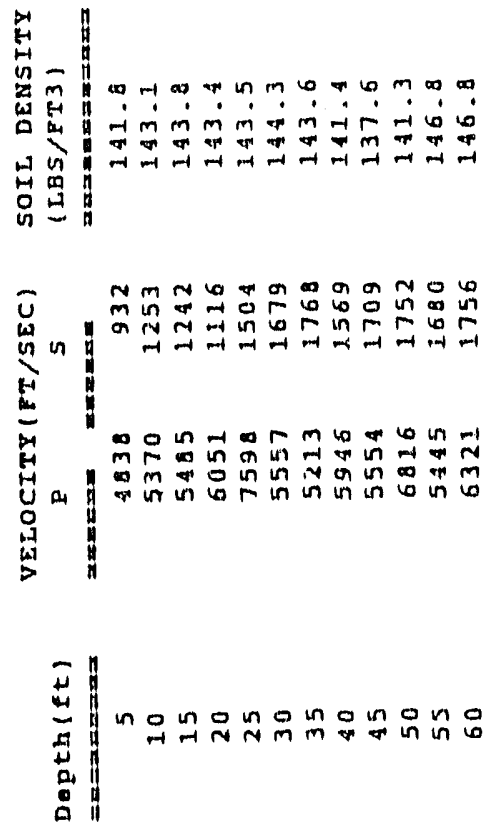

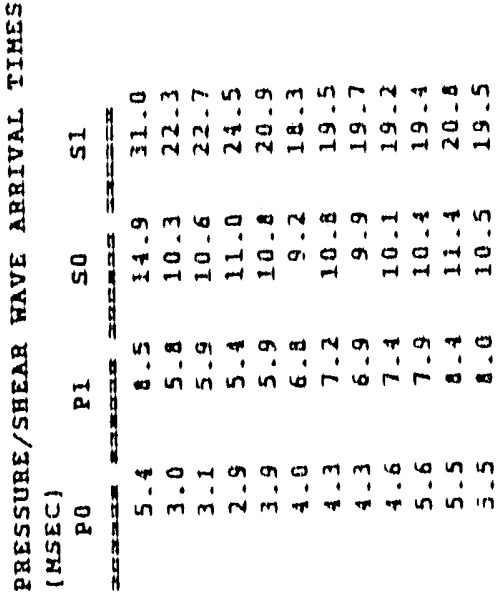

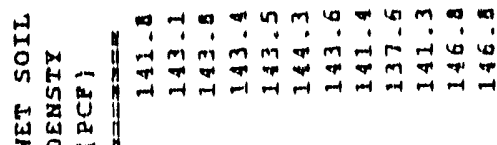

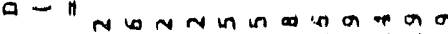

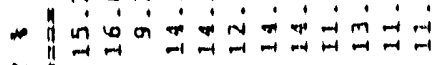
焉
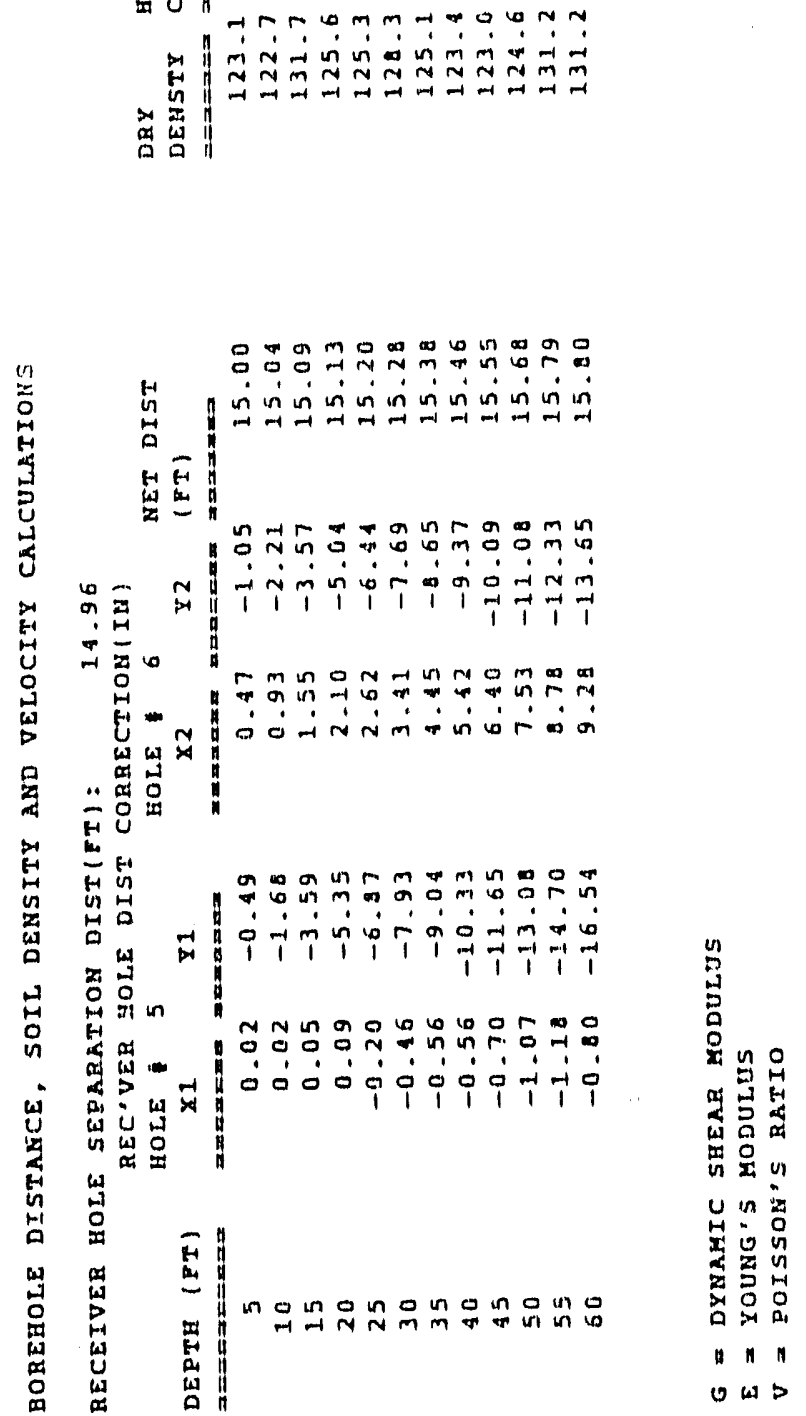

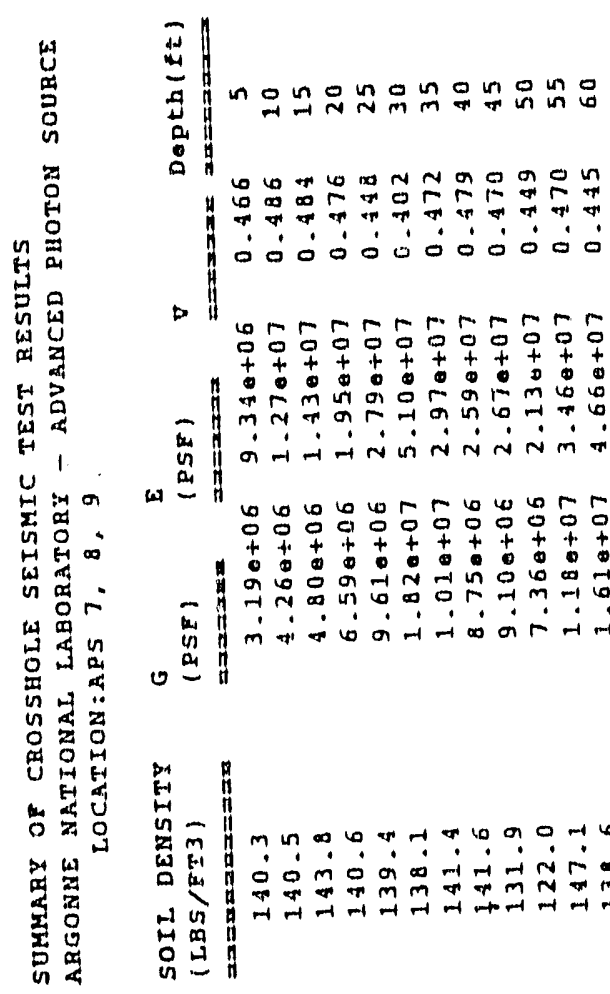

"

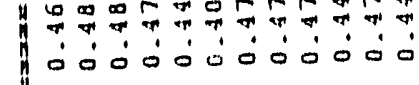
b.

warmmrrmr

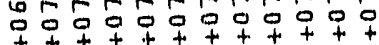

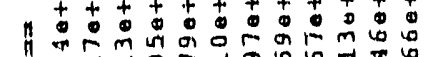
की w

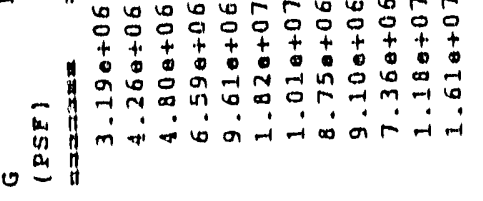
等

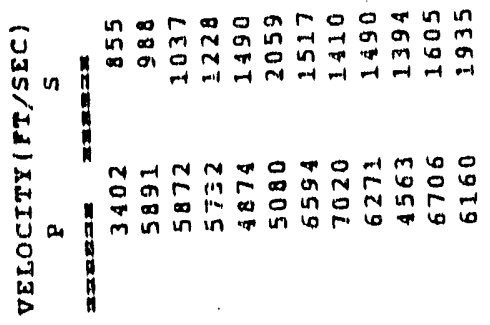

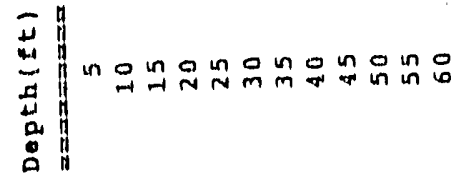

瓷

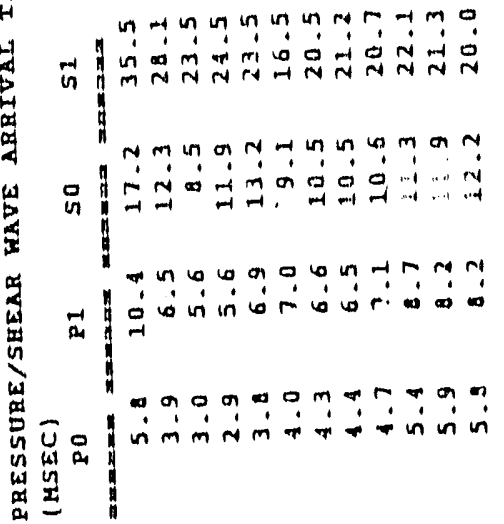

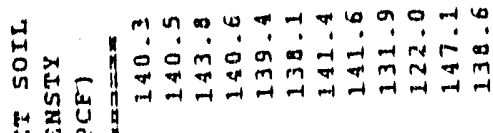

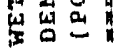

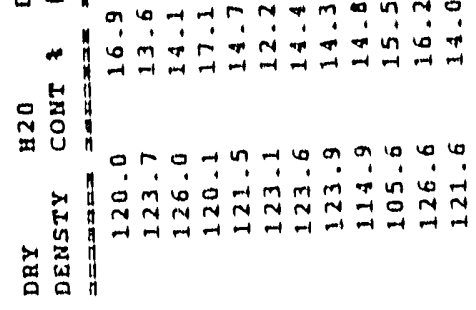

$$
\text { 咨 }
$$

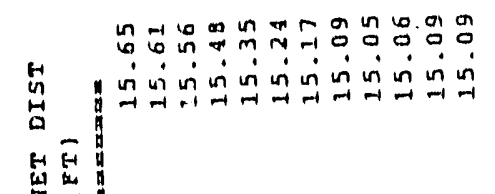

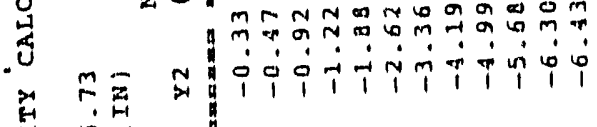

点

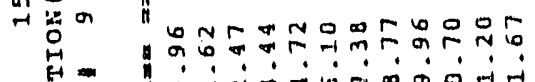

出

层

 

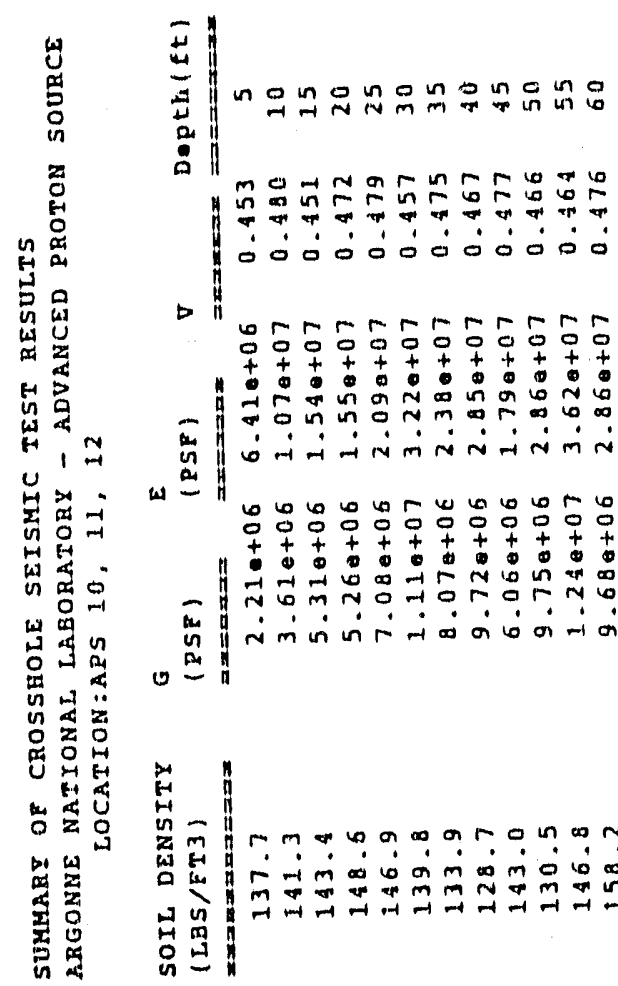

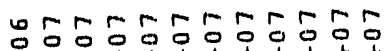

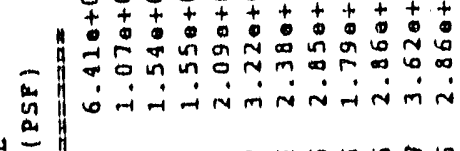

ผ - "

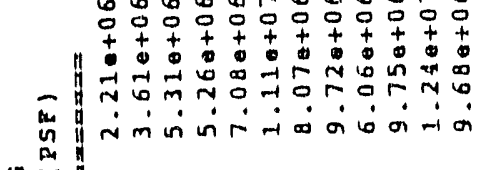

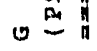
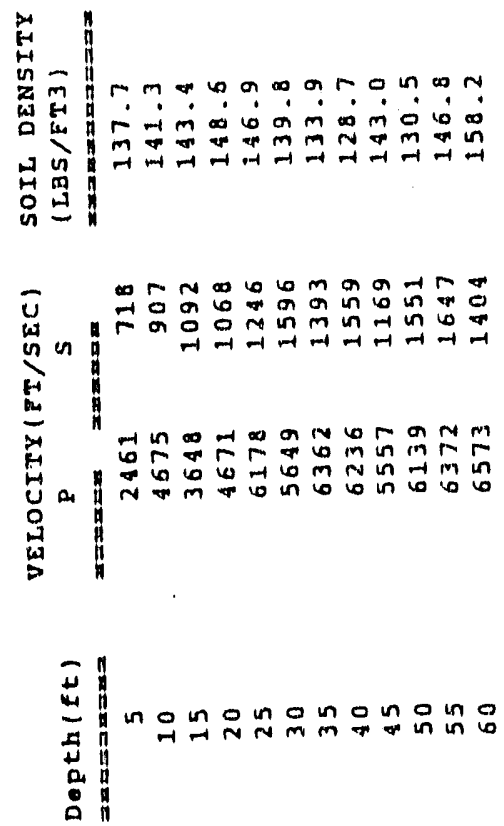
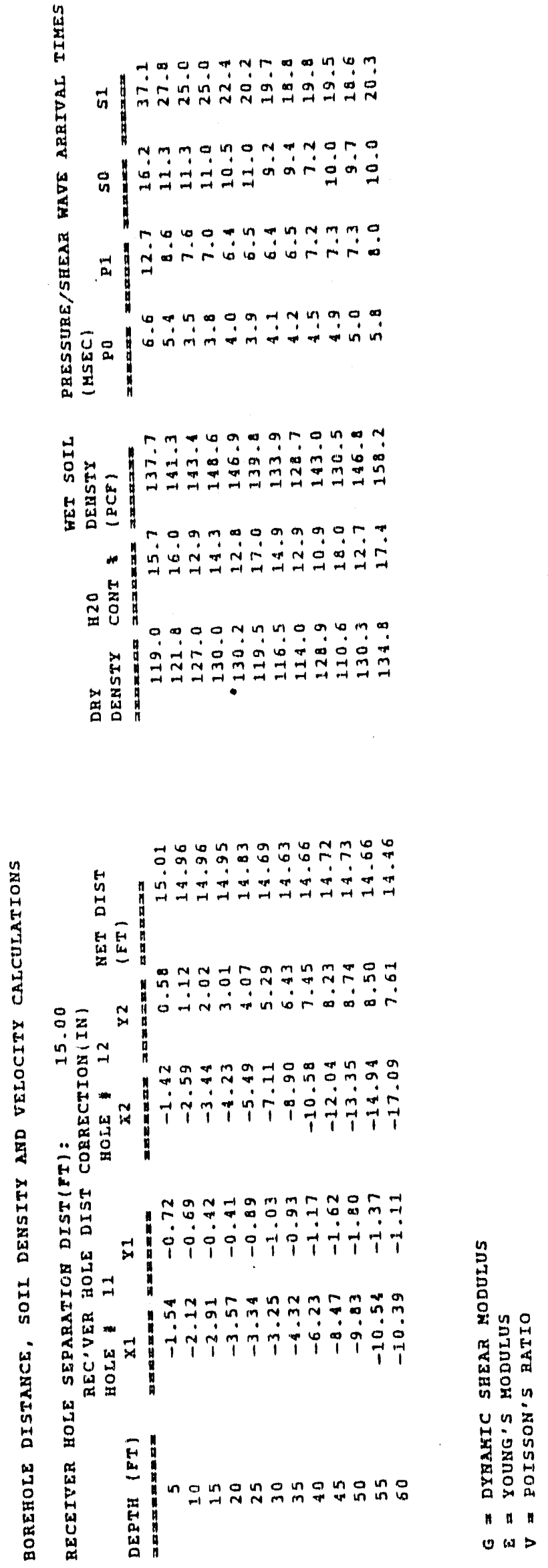


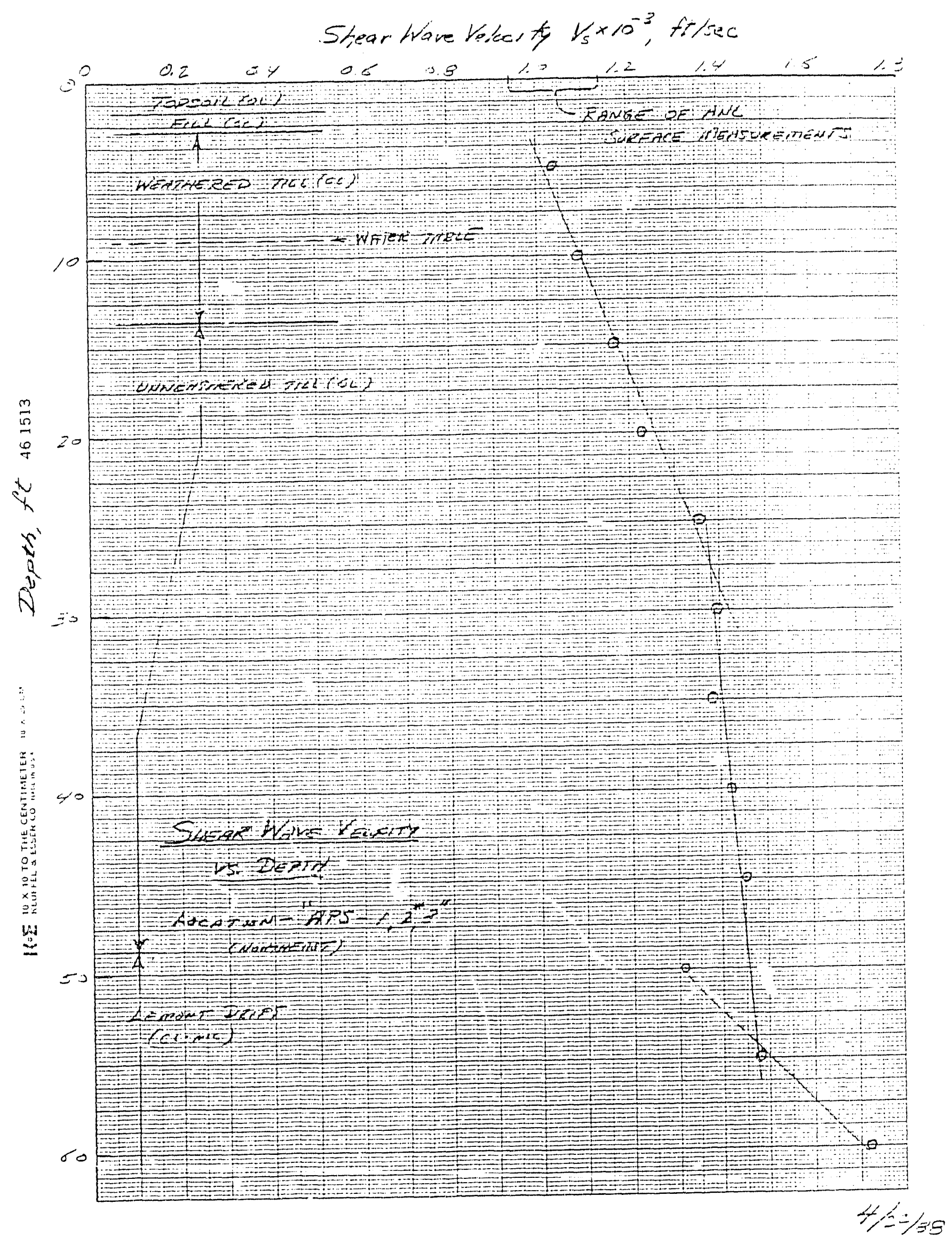

Fig. A-1. Silear wave velocity vs. depth (Boreholes APS-1, 2, 3) 


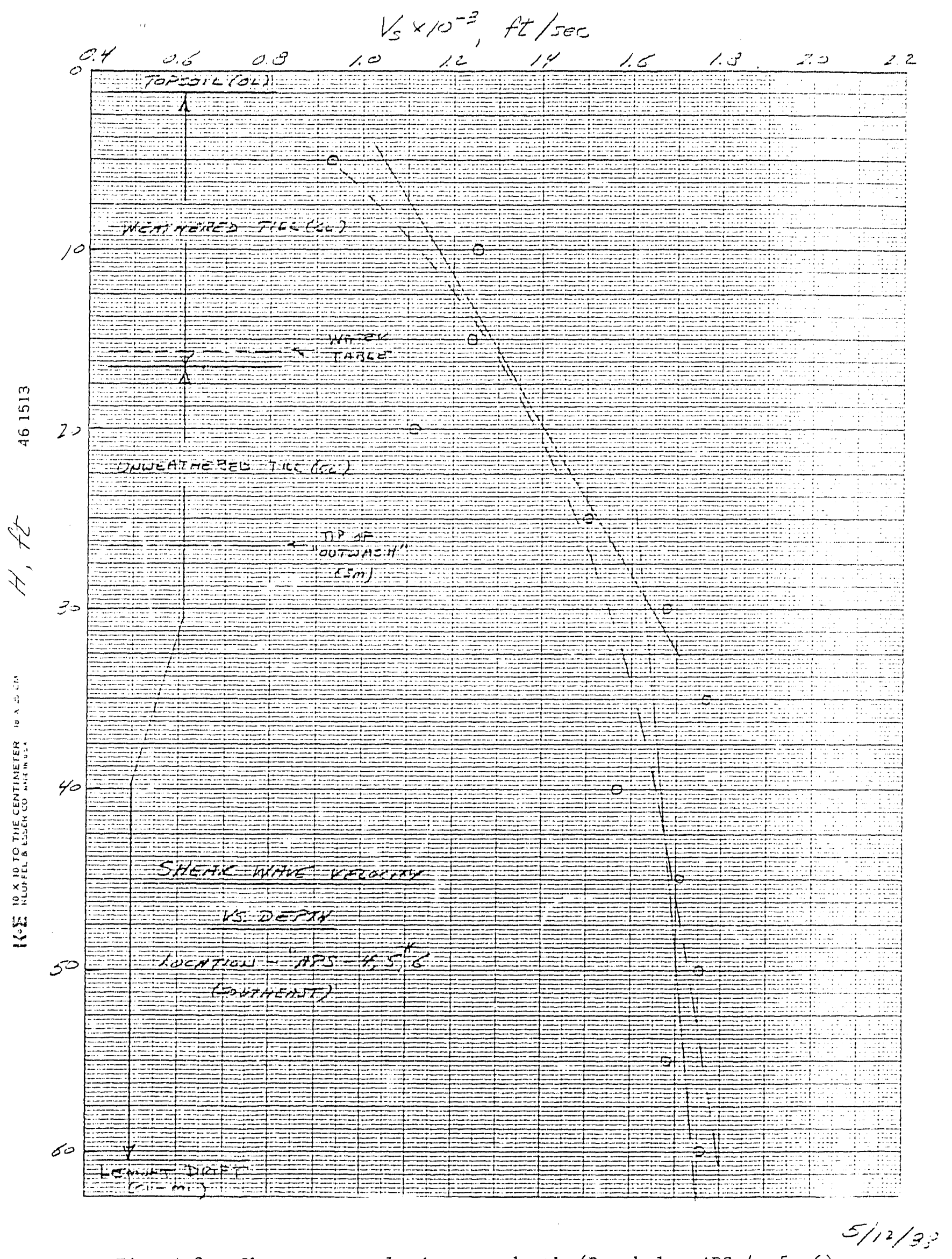

Fig. A-2. Shear wave velocity vs. depth (Boreholes APS-4, 5, 6) 


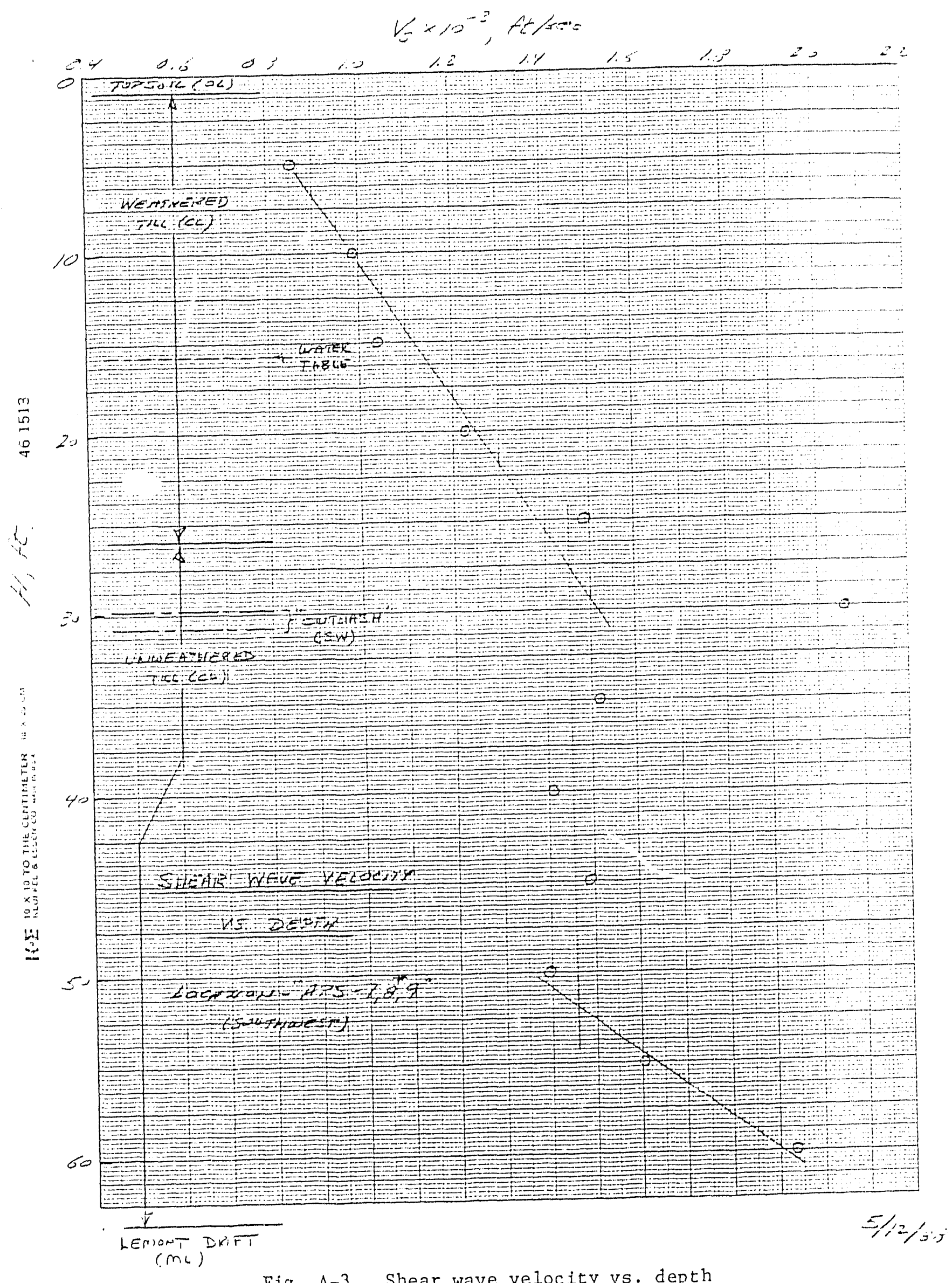

Fig. A-3. Shear wave velocity vs, depth 


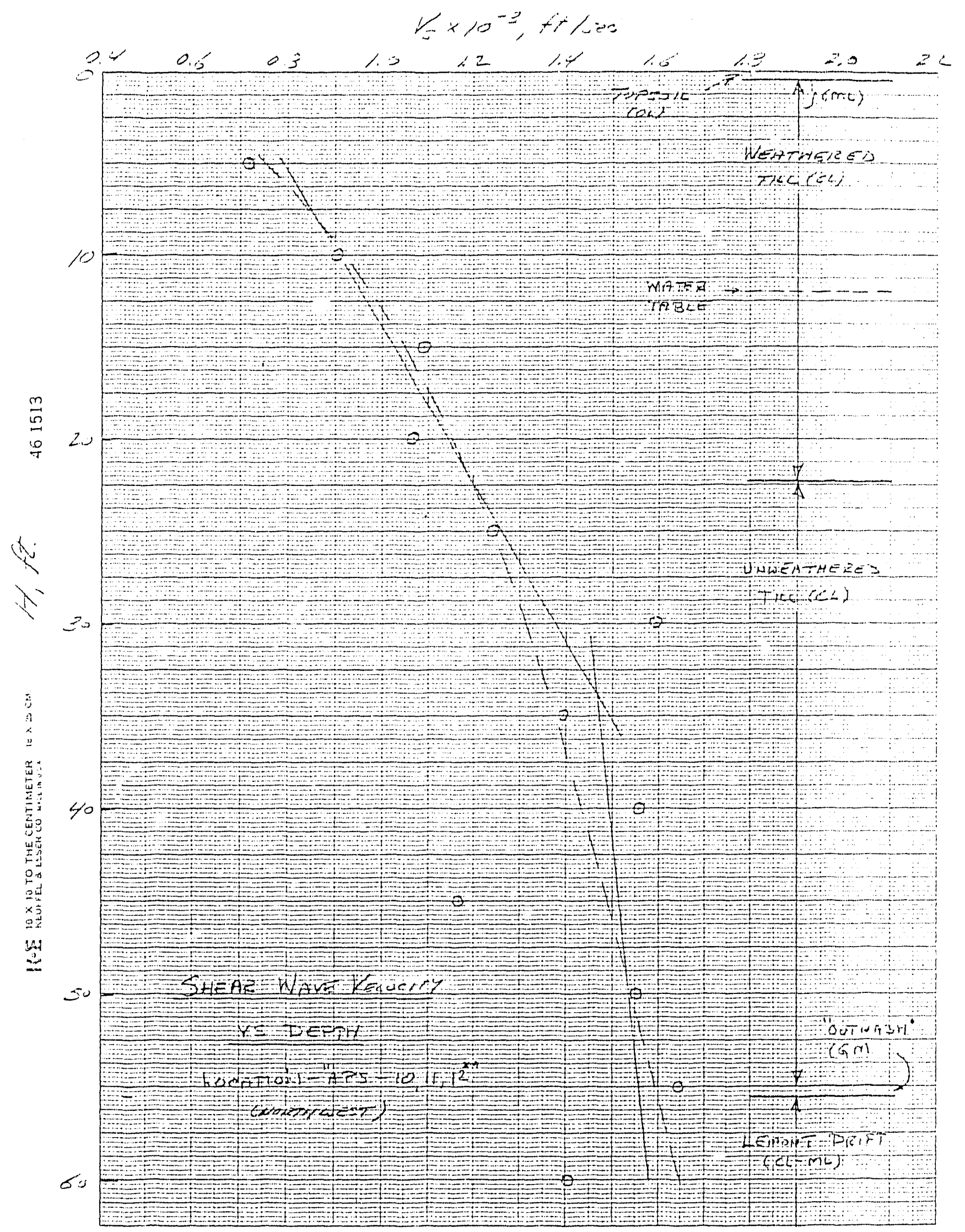

Fig. A-4. Shear wave velocity ys. depth (Boreholes APS-10, 11, 12) 


\section{Table A-1 Unified Soil Classification}

$\mathrm{OL}$ - Organic silts and organic silty clays of low plasticity

ML - Inorganic silts and very fine sands, rock flour, silty or clayey fine sands or clayey silts with slight plasticity

$\mathrm{CL}$ - Inorganic clays of low to medium plasticity, gravelly clays, sandy clays, silty clays, lean clays

SM - Silty sands, sand-silt mixtures

SW - Well-graded sands, gravelly sands, little or no fines

\section{DISCLAIMER}

This report was prepared as an account of work sponsored by an agency of the United States Government. Neither the United States Government nor any agency thereof, nor any of their employees, makes any warranty, express or implied, or assumes any legal liability or responsjbility for the accuracy, completeness, or usefulness of any information, apparatus, product, or process disclosed, or represents that its use would not infringe privately owned rights. Reference herein to any specific commercial product, process, or service by trade name, trademark manufacturer, or otherwise does not necessarily constitute or imply its endorsement, recommendation, or favoring by the United States Government or any agency thereof. The views and opinions of authors expressed herein do not necessarily state or reflect those of the United States Government or any agency thereof. 

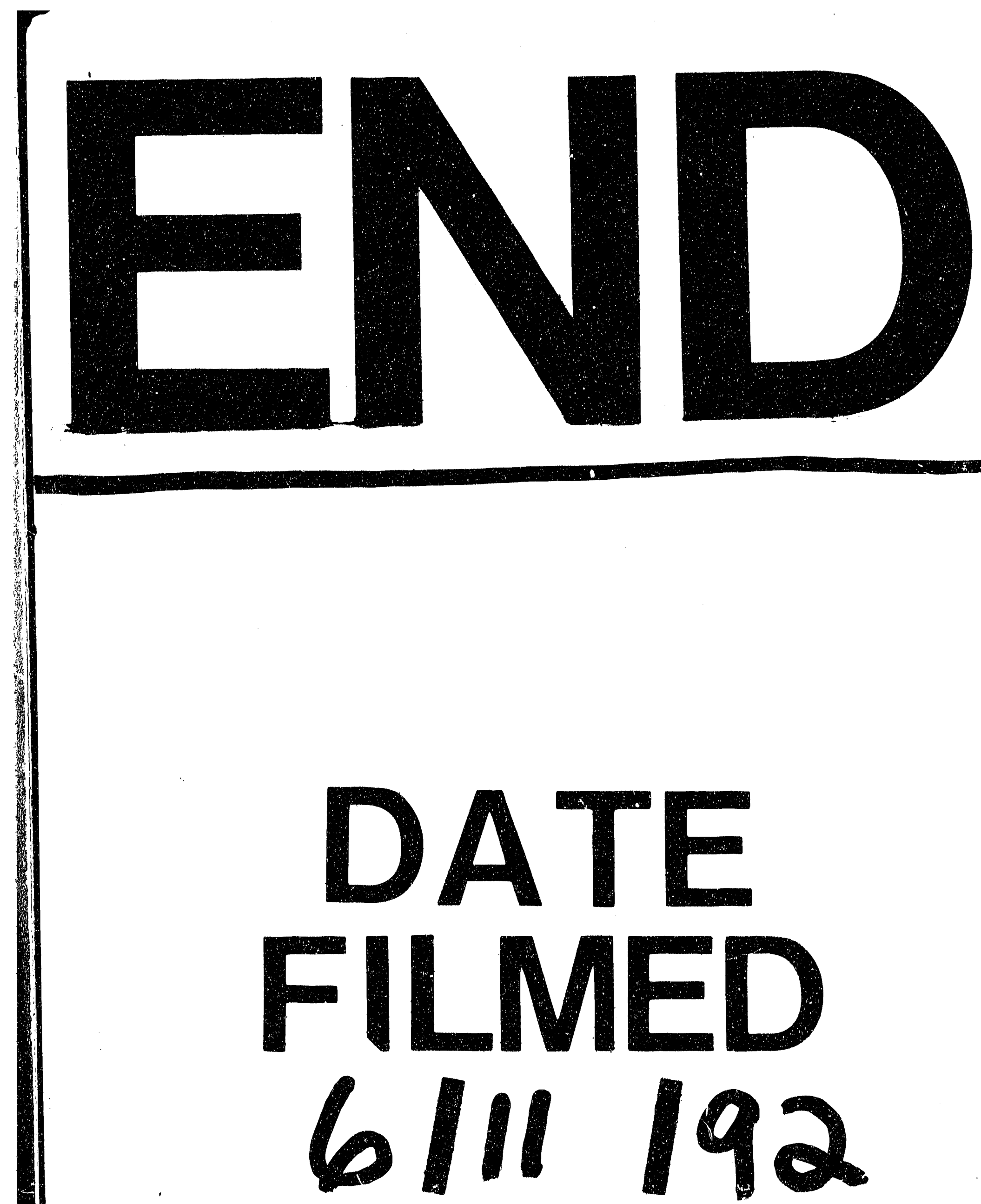
